\title{
Evaluation of Fatigue Potential for Crumb Rubber Modified Bitumen in Stone Mastic Asphalt Mixes
}

\author{
Anusha T M, Sharath Kumar M D, H S Jagadeesh
}

\begin{abstract}
SMA is a gap graded mix composed of a high concentration of coarse aggregate that is held together in a thick asphalt film by a matrix of mineral filler and stabilizers. Since natural aggregates have become expensive, hence Reclaimed Asphalt Pavement (RAP) can be reused in pavement construction to reduce the environmental hazardous due to disposal problems. Since the RAP contains used aggregates, it is highly prone to fatigue, thermal and reflective cracking effect. Rheological and chemical properties of aged bitumen in RAP can be enhanced by use of untreated waste oils such as waste engine oil as rejuvenators. This research presents a study on fatigue performance of SMA mix with Reclaimed Asphalt Pavement (RAP) materials with and without rejuvenators and results were compared with conventional SMA mix. The materials used were first characterized by common laboratory tests. Then the three SMA mixes are tested using several laboratory test procedures: Marshall Stability, indirect tensile strength, moisture susceptibility, and indirect tension fatigue test. The optimum proportions of the of the mixes with highest stability are selected from the Marshall stability test. The indirect tensile strength test results show that the SMA mix replaced with RAP without rejuvenators showed higher tensile strength ratio and resistance to moisture damage when compared to conventional mix and optimum RAP replacement mix with rejuvenators. The fatigue test was conducted for the three optimum mixes at different temperature and stresses. The fatigue test results showed that at lower temperature and stresses, the RAP replaced SMA withou rejuvenator offered better fatigue resistance than those with rejuvenator and conventional SMA mix. At higher temperatures, the RAP replaced SMA mix with rejuvenator offered similar fatigue lifecycle as conventional mix. However, at high stresses, conventional SMA mix offered better fatigue lifecycle. Increase in failure stresses resulted in decrease of number of fatigue cycles and increased in initial tensile strain of the mix. Thus, with the use of RAP substantial decrease in cost can be achieved without compromising the fatigue characteristic of the SMA mix.
\end{abstract}

Keywords: Then the three SMA mixes are tested using several laboratory test procedures: Marshall Stability,

\section{INTRODUCTION}

Stone mastic asphalt (SMA) was developed by Dr. Zincher of the Straubag-Bau central laboratory Germany in the 1960s, to resist the damage caused by studded tires.

Manuscript received on September 09, 2021.

Manuscript published on September 30, 2021.

* Correspondence Author

Anusha T M, PhD Student Research Scholar, Department of Civil Engineering, Bhusanayana Mukundadas Sreenivasaiah College of Engineering, Bengaluru, (Karnataka), India.

Sharath Kumar M D, Department of Civil Engineering, Bhusanayana Mukundadas Sreenivasaiah College of Engineering, Bengaluru, (Karnataka), India.

Dr. H S Jagadeesh, Professor, Department of Civil Engineering, Bhusanayana Mukundadas Sreenivasaiah College of Engineering, Bengaluru, (Karnataka) India.

(C) The Authors. Published by Blue Eyes Intelligence Engineering and Sciences Publication (BEIESP). This is an open access article under the CC BY-NC-ND license (http://creativecommons.org/licenses/by-nc-nd/4.0/)
Revised Manuscript received on September 16, 2021.

SMA is a gap graded mixture containing $70-80 \%$ coarse aggregate of total aggregate mass, $6-7 \%$ of binder, $8-12 \%$ of a filler, and about $0.3-0.5 \%$ of fibre or modifier. A skeletontype structure is formed due to the high amount of coarse aggregate in the mixture providing better stone-on-stone contact between the coarse aggregate particles, which offers high resistance to rutting. The SMA has its deformationresistant capacity from a coarse stone skeleton providing more stone-on-stone contact than with conventional dense graded asphalt (DGA) mixes. Improved binder durability results from higher bitumen content, a thicker bitumen film, and lower air voids content. The cellulose fibre is used to reduce the air voids this high bitumen content also improves flexibility. The addition of a small quantity of cellulose or mineral fibre prevents drainage of bitumen from the matrix during transport and placement. (Patel et al. 2016) (Yastremsky et al. 2018)

When the pavement grows older, the aged binder becomes more brittle and loses its strength resulting in loss of pavement service life, and under these circumstances, the pavement surfaces can be removed which is generally known as Reclaimed Asphalt Pavement (RAP). However, as the aged bitumen in RAP is more brittle than fresh bitumen and is highly vulnerable to fatigue, thermal, and reflective cracking, experts suggest using RAP content of 10 to 30 percent for new HMA mix (Joni et al. 2019). By using rejuvenators, rheological and chemical properties of RAP binder can restored and more quantity i.e., up to $80 \%$ of RAP can be incorporated in the new HMA mix. As a result, of this construction of pavements with RAP is seeing an increasing trend. The use of RAP in the HMA mix makes it very economical and also provides added environment benefits by making reducing the disposal problem of RAPs Owing to the aging and climatic cycles, oxidation causes the traffic load to stiffen the bitumen, which in effect contributes to fatigue distress, contributes to pavement cracks, and continues in the pavements layers, resulting in the potholes and stripping of the layers. (Shen et al. 2007) Usually, an asphalt binder that experiences aging of oxidization has a lower concentration of more reactive components [Nitrogen base $(\mathrm{N})+$ first acidifies (A1)] and the higher concentration of less reactive components [Paraffines (P) + second acidifies (A2)]. Generally, a rejuvenator used for restoring the aged asphalt binders has a minimum N/P ratio of 0.5 to ensure the compatibility of the rejuvenator and the aged binder and to prevent syneresis (i.e., contraction of a gel accompanied by the separating of liquid). The condition for bitumen being stiffer is the reduction of the binder's aromatic content while increasing the number of resins (i.e., increase asphaltenes content).

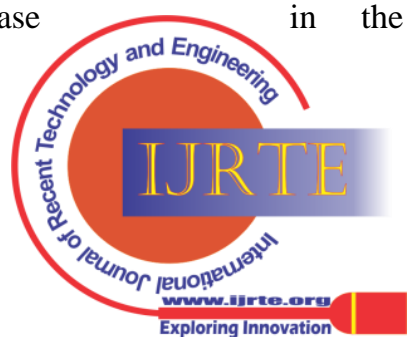


Rejuvenators can restore the original asphaltenes to maltenes ratio in the aged asphalt pavements to plasticize the aged asphalt and produce a broad-spectrum renovation that compensates the volatile materials and disperses oils while promoting the adhesion. (Tran et al. 2016) (Mazzoni et al. 2018) (Joni et al. 2019).

Crumb rubber (CR) when blended with asphalt binder, yields a product that is generally called asphalt rubber (AR). Enhancement of the anti-fatigue property of the mixture with the addition of crumb rubber into asphalt mixtures can be based on the following two reasons. One is that crumb rubber powder consists of an anti-aging element, such as carbon black, which increases the aging resistance of the mixtures and the other reason is that crumb rubber increases the viscosity and the elasticity of the asphalt binder thereby, improving the asphalt film thickness on the surface of the aggregates and subsequently increases the asphalt mixtures aging resistance. Many studies show that adding crumb rubber could significantly improve the intermediate temperature fatigue life of asphalt binders. (Zaumanis et al. 2016) (Mashaan et al. 2013)

Fatigue cracking is one of the vital distress of asphalt pavement. Fatigue cracking is a phenomenon that occurs in pavements due to repeated applications of traffic loads. Indian traffic is a heterogeneous type. Due to the repeated traffic loading combined with the ultraviolet-irradiation aging, the adhesive and cohesive performance of asphalt mastic deteriorates, leading to the development of fatigue cracks, surface texture roughness, and potholes eventually the disintegration of the whole pavement surface. The fatigue life of asphalt materials can be predicted using the methods such as the Superpave fatigue factor $\left(\mathrm{G}^{*} \sin \delta\right)$ test and linear amplitude sweep (LAS) test for asphalt binder, the sheer fatigue test for asphalt mortar, and the indirect tensile fatigue test (ITFT) and four-point bending beam (4PB) test for asphalt mixture (Wang et al. 2020). Indirect Tensile strength is measured to know the wet and dry load of the sample and this load is used to calibrate the fatigue distress while testing in the fatigue testing machine. Resilient modulus is one of the important properties in the mechanistic analysis of pavement response under dynamic traffic loads and to measure the quality of the materials. It measures the potential elastic properties of the asphalt mix (Ariyapijati et. al. 2017). The number of factors influencing resilient modulus is test temperature, loading time or loading frequency, rest period, and loading pulse waveforms. Field aging of aged binder can be measured by various methods such as are Thin Film Oven Test (TFOT) and Rolling Thin Film Oven Test (RTFOT) for short term aging while Pressure Aging Vessel (PAV) and Rotating Cylinder Aging Test (RCAT) are specifically for long term aging which involves in measuring Oxidation and Volatile losses. Although resilient modulus includes different parameters, it also changes concerning aging phenomena of asphalt mixtures, which made research into the aging asphalt mixture phenomenon. (Karami et al. 2017) (Li et al.2018) (Xiao et al.2011)

\section{MATERIALS}

\section{A. Natural aggregates}

The composite aggregate consists of the coarse, medium, and fine aggregate with a maximum $19 \mathrm{~mm}$ thickness. Fine aggregate consists of the manufactured sand resulting from crushing operations going through a sieve of 2,36 mm and held on a sieve of $0,075 \mathrm{~mm}$. Aggregates of for this study are collected from KMS crusher, Bagalur, Tamilnadu. The properties of aggregates are summarised in Table 1.

B. Reclaimed Asphalt Pavement (RAThe RAP materials is procured from NH-206, where the existing 2 lane flexible pavement is removed to construct the cement concrete pavement near the Karnataka-Andhra Pradesh border. The pavement was found to be approximately 15 - 20 years old as per the records. Table I shows the results of common laboratory tests for RAP aggregates.

Table- I: Properties of natural and RAP aggregates

\begin{tabular}{|c|c|c|c|c|}
\hline Property & Test & $\begin{array}{c}\text { Natural } \\
\text { Aggregates }\end{array}$ & RAP aggregates & $\begin{array}{c}\text { IRC-SP: 79 (2008) } \\
\text { Specifications }\end{array}$ \\
\hline Particle shape & Combined EI \& FI & $10.51 \%$ & $22.68 \%$ & Max $30 \%$ \\
\hline Strength & Aggregate crushing & $23 \%$ & $19.56 \%$ & Max $30 \%$ \\
\hline Toughness & Aggregate Impact value & $17.51 \%$ & $9.73 \%$ & Max $18 \%$ \\
\hline Water absorption & Water absorption & $0.4 \%$ & $0.55 \%$ & Max $2 \%$ \\
\hline Specific gravity & Specific gravity & 2.734 & 2.66 & $2.5-2.8$ \\
\hline
\end{tabular}

\section{Crumb Rubber Modified Bitumen (CRMB)}

CRMB is the hydrocarbon binder obtained through physical and chemical interactions of crumb rubber (produced by recycling of used tires) with bitumen and some particular additives. CRMB-55 was collected from the
Mangalore Refineries and Petrochemicals Limited (MRPL). Table II presents the results of common laboratory tests on the CRMB 55 sample obtained.

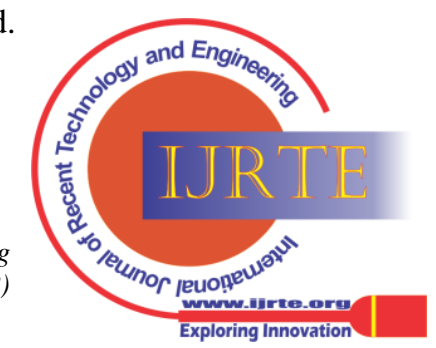


Table- II: Physical Properties of CRMB-55

\begin{tabular}{|c|c|c|c|}
\hline SL No. & Test & CRMB-55 results & $\begin{array}{c}\text { Specifications as per } \\
\text { MoRT\&H }\end{array}$ \\
\hline 1 & Penetration at $25^{\circ} \mathrm{C}$, min & 47 & $60(\max )$ \\
\hline 2 & Softening point ( $\mathrm{R} \& \mathrm{~B}),{ }^{\circ} \mathrm{C}$ & 56.75 & 55 (min) \\
\hline 4 & $\begin{array}{l}\text { Elastic Recovery of half thread in ductilometer at } 15 \\
{ }^{\circ} \mathrm{C},{ }^{\circ} \mathrm{C}\end{array}$ & 50 & 50 (min) \\
\hline 5 & Separation test, the difference in softening point, ${ }^{\circ} \mathrm{C}$ & 3.5 & $4(\max )$ \\
\hline \multirow{4}{*}{6} & $\begin{array}{cc}\text { a) } & \text { Loss in mass, } \% \\
\end{array}$ & 0.7 & $1.0(\max )$ \\
\hline & b) Increase in softening point, ${ }^{\circ} \mathrm{C}$ & 1.3 & $6(\max )$ \\
\hline & $\begin{array}{l}\text { c) Reduction in penetration of residue at } 25 \\
{ }^{\circ} \mathrm{C}, \%\end{array}$ & 25.20 & 40 (max) \\
\hline & $\begin{array}{c}\text { d) Elastic Recovery of half thread in } \\
\text { ductilometer at } 15^{\circ} \mathrm{C}, \%\end{array}$ & 37 & 35 (min) \\
\hline
\end{tabular}

\section{Rejuvenators - Waste Engine Oil (WEO)}

Engine lubricating oil is made from paraffinic base oils with a small dose of specialty compounds added to boost the viscosity, stability, cleaning (ability to extract contaminants from cylinder walls and oil pathways), and flammability. Waste engine oil (WEO) is also made up of short-chain polar molecules that can break apart during lubricating operation. Research has shown that bus/truck engine oil is better suited than engine oil for small vehicles. So, WEO is collected from Hassan Bus Depot for the current work.

\section{E. Mineral Filler and Stabilizer Additive}

Mineral Filler consists of finely divided minerals such as stone dust or hydrated lime that passes through a sieve of $0.075 \mathrm{~mm}$. The mineral filler is chosen so it meets SMA's grading criteria. Baghouse dust is the dust or particulate matter collected from baghouse filter, bag filter or cloth filter which is an air pollution control system and dust collector that removes particulate matter or gas emitted from commercial establishments from the air. The baghouse dust for this study is acquired from Sri Venkateshwara Crushers, Periyapatna.

Cellulose fibers can be used in the SMA mix only in the pelletized form. The dosage rate for cellulose fibers is $0.3 \%$ minimum by weight of the total mix. For this work, it is obtained by "Strategic Marketing and Research Team".

By utilizing the different materials mentioned above, final gradation of conventional SMA mix is arrived and can be observed from the Fig. 1. Table III shows the final proportion of materials in the conventional SMA mix.

Table-III: Proportion of different aggregate sizes

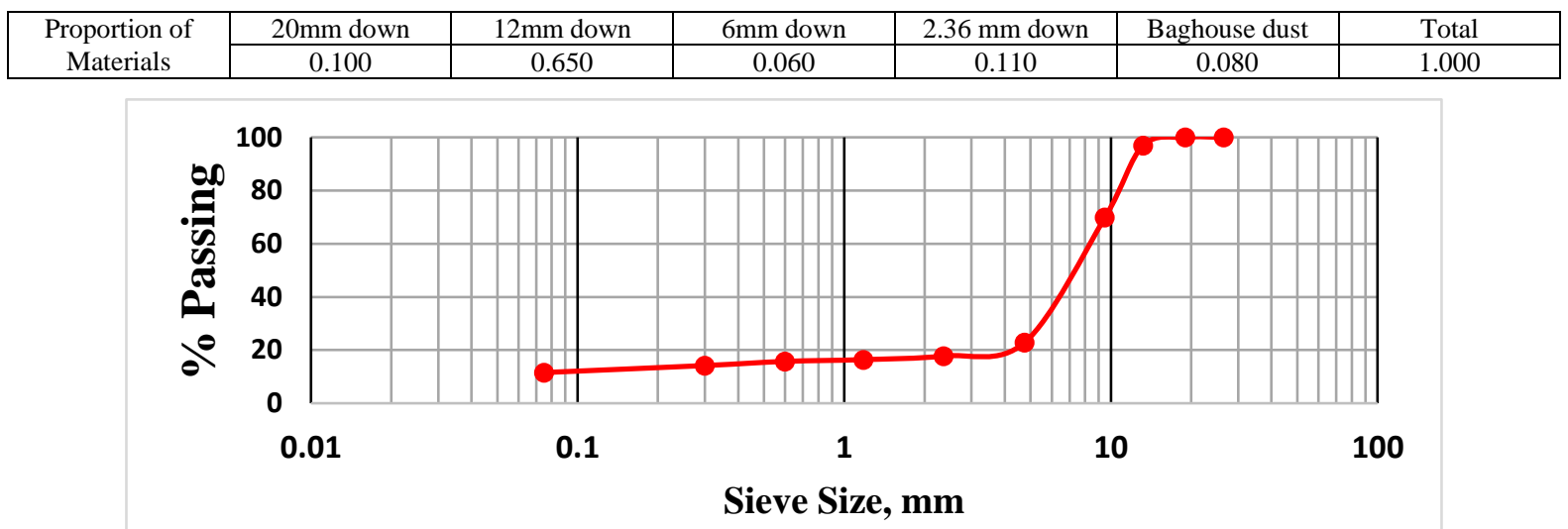

Fig. 1: Gradation of conventional SMA mix

\section{MIX DESIGN}

The SMA mix design as per requirements AASHTO PP4101 and IRC- SP: 79-2008. The measures followed are as shown below

1. Selection of material.

2. Selection of good gradation.

3. Determination of the VCA, aged bitumen content.

4. Determination of the Optimum Binder Content.

5. Performing the Marshall Stability, Indirect Tensile Strength, and Fatigue test.

\section{A. Mix Preparation}

Natural and RAP aggregates are procured from the quarry and removed pavement surfaces concerning the SMA specifications as recommended by IRC- SP:79-2008. The

aggregates are graded using the Roth futch process, and the proportion of the mixture is calculated. Bitumen rheology is performed to identify the concentration of the aged binder on RAP. Marshall moulds are prepared for three different mixture types; Natural Aggregate, Natural Aggregate + RAP, and Natural Aggregate + RAP + rejuvenator (WEO) by mixing with CRMB-55, mineral fillers and stabilizer additives (cellulose fibers). Specimens in triplicates with dimensions of $101.6 \pm 0.5 \mathrm{~mm}$ diameter \& 57-70 mm height were compacted by applying 50 blows on either side according to the ASTM D 6926 guidelines for Marshall Compaction.

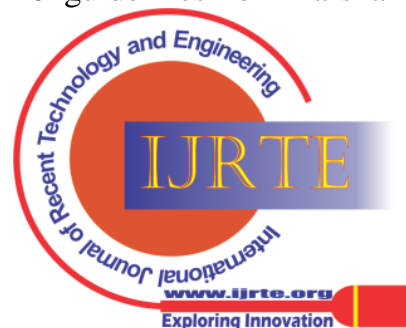


Marshall Stability Test is conducted to determine Optimum Binder Content (OBC), Stability and Flow value of above three different mixes as per AASHTO T 245 (ASTM D 6927). Indirect Tensile Strength test known to be Water Sensitivity test is conducted to find out Voids analysis by using Job Mix Formula and to set the blows which would give voids of $6 \pm 0.5 \%$ in the sample with compliance of AASHTO T 269 (ASTM D 3203). To assess the water sensitivity of the mix as per AASHTO T 322 (ASTM D 4123) the ITS test is performed for both conditioned and unconditioned samples. Then ITS dry load is taken using the Marshall assembly which is used as stress values in a repeated loading haversine waveform test apparatus as per ASTM D 4123 for performing fatigue and resilient modulus test. The preparation of specimens is the same as that prepared for the Marshall moulds with 50 blows on either side to achieve a void ratio of between $3 \%$ and $5 \%$

\section{RESULTS AND DISCUSSION}

\section{A. Marshall Stability Test}

The Marshall Stability test is conducted on three SMA samples; conventional SMA mix, SMA mix with RAP replacement and SMA mix with RAP and rejuvenator addition. The test is conducted with various proportions of Binder, RAP and rejuvenators content. From the results, the optimum proportions of three SMA mixes are selected from the samples having highest Marshal Stability. The optimum proportions are

i. Conventional SMA mix with binder content (CRMB) of 6\%

ii. SMA mix with $40 \%$ of RAP replacement

iii. SMA mix with $70 \%$ of RAP replacement and addition of $25 \%$ Waste engine oil (WEO) as rejuvenator

Table IV summarizes the properties obtained from the Marshall Stability test for the optimum samples

Table- IV: Marshall Properties of SMA mix

\begin{tabular}{|c|c|c|c|c|}
\hline SI No. & Properties & $\begin{array}{c}\text { Conventional SMA } \\
\text { mix + 6\% CRMB-55 }\end{array}$ & $\begin{array}{c}\text { SMA mix + 40\% RAP } \\
+ \text { CRMB-55 }\end{array}$ & $\begin{array}{c}\text { SMA mix + 70\% RAP } \\
+ \text { CRMB-55 + } \\
\mathbf{2 5 \% W E O}\end{array}$ \\
\hline 1 & Marshall Stability (kN) & 8.59 & 13.20 & 11.62 \\
\hline 2 & Flow (mm) & 3.8 & 3.20 & 3.19 \\
\hline 3 & Volume of voids (\%) & 4 & 4.04 & 3.99 \\
\hline 4 & VMA (\%) & 18 & 17.96 & 17.88 \\
\hline 5 & VFB (\%) & 77.5 & 77.50 & 77.70 \\
\hline
\end{tabular}

\section{B. Indirect Tensile Strength (ITS)}

The ITS test is performed on three optimized SMA samples in both unconditioned and conditioned states for the wearing course. Table V provides the summary of ITS test results for all three samples. The Tensile Strength Ratio, which is the ratio of conditioned sample to unconditioned sample, for Conventional SMA mix, SMA mix with RAP replacement with and without WEO are 89.83, 91.40 and 90.99 respectively. Thus, it is clear that SMA mix with RAP offers higher moisture resistance and tensile strength than SMA mix with RAP and rejuvenator. Both the RAP replaced samples offer better moisture susceptibility than conventional SMA mix.

Table-V: Summary of ITS test results of SMA mixes

\begin{tabular}{|c|c|c|c|}
\hline SMA mix & Conditioned & Unconditioned & $\begin{array}{c}\text { Tensile Strength Ratio } \\
\text { (TSR) }\end{array}$ \\
\hline $\begin{array}{c}\text { Conventional SMA mix + 6\% } \\
\text { CRMB-55 }\end{array}$ & 500.92 & 557.65 & 89.83 \\
\hline $\begin{array}{c}\text { SMA mix + } \% \text { RAP + CRMB- } \\
55\end{array}$ & 840.66 & 919.76 & 91.40 \\
\hline $\begin{array}{c}\text { SMA mix + } \\
55 \text { RAP + CRMB- }\end{array}$ 25WEO & 716.10 & 787.03 & 90.99 \\
\hline
\end{tabular}

\section{Indirect Tensile Fatigue Test}

The fatigue test is conducted on the conventional SMA mix and optimized RAP with and without the rejuvenator in ITFT apparatus. The specimen is tested at three different temperature $\left(25^{\circ} \mathrm{C}, 35^{\circ} \mathrm{C}\right.$ and $\left.45^{\circ} \mathrm{C}\right)$ and four stress levels $(10 \%, 20 \%, 30 \%$ and $40 \%$ of failure stress). The specimen is deemed to be failed when it undergoes vertical deformation of $5 \mathrm{~mm}$ due to fatigue loading. The Figs $2-10$ shows the log-log plot of fatigue cycles vs Micro strain (horizontal tensile strains) for three types of sample mixes at three temperature. The figures also provides the respective regression equation of the form $\log \mathrm{N}_{\mathrm{f}}=\log \mathrm{k}_{1}+$ $\mathrm{k}_{2} \log \varepsilon$. Table 6 gives summary of regression equation obtained from the Fatigue test.
It can be observed from the above figures and summarized data, the $\mathrm{y}$ - intercept $\left(\log _{1}\right)$ of regression equation represents the number of fatigue cycle at failure for unit strain. At lower room temperatures (i.e., $25^{\circ} \mathrm{C}$ and $35^{\circ} \mathrm{C}$ ), the intercept is highest for SMA mix with RAP and WEO followed by SMA mix with RAP and conventional SMA mix respectively. It indicates that, at lower temperature, the mix with RAP and WEO requires more cycle of load to fail than other two and hence is more stable. At higher temperature (i.e., $45^{\circ} \mathrm{C}$ ), the Conventional SMA mixture appears to be more stable than the mix with RAP replacement and have almost similar stability as the SMA mix with RAP and rejuvenator replacement.

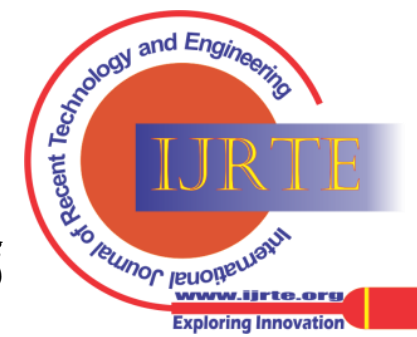




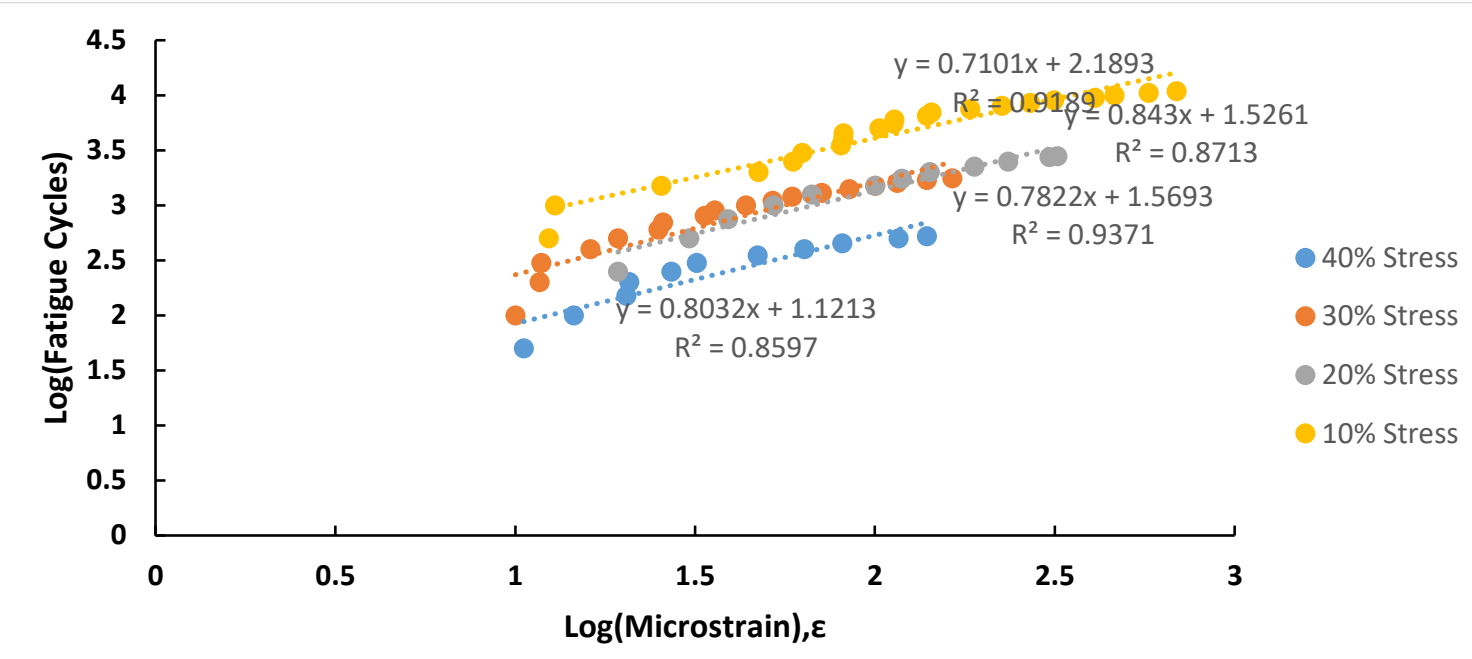

Figure 2: $\mathbf{L o g}-\mathrm{Log}$ plot of Fatigue Cycles vs Micro strain for conventional SMA mix at $25^{\circ} \mathrm{C}$

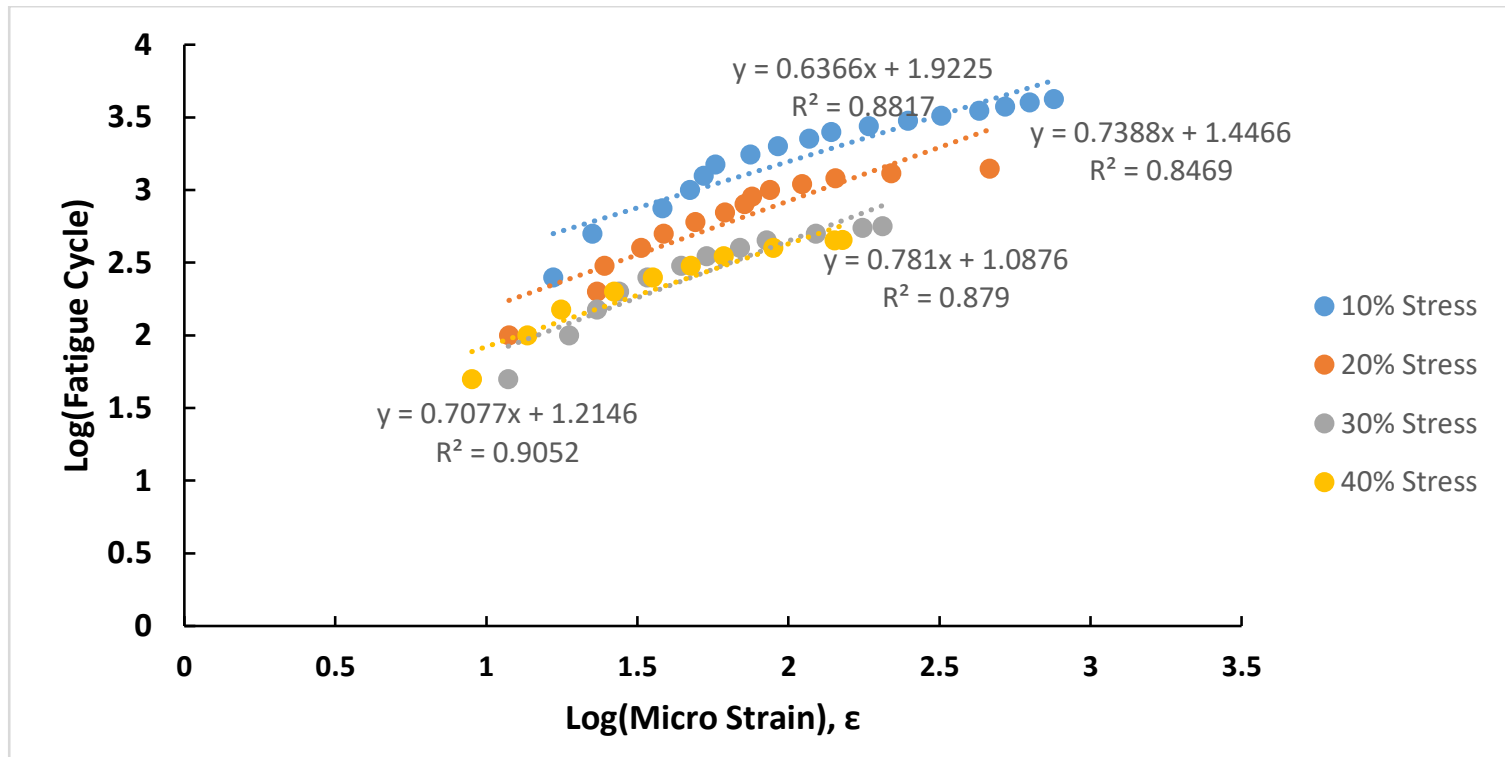

Figure 3: $\log -\log$ plot of Fatigue Cycles vs Micro strain for conventional SMA mix at $35^{\circ} \mathrm{C}$

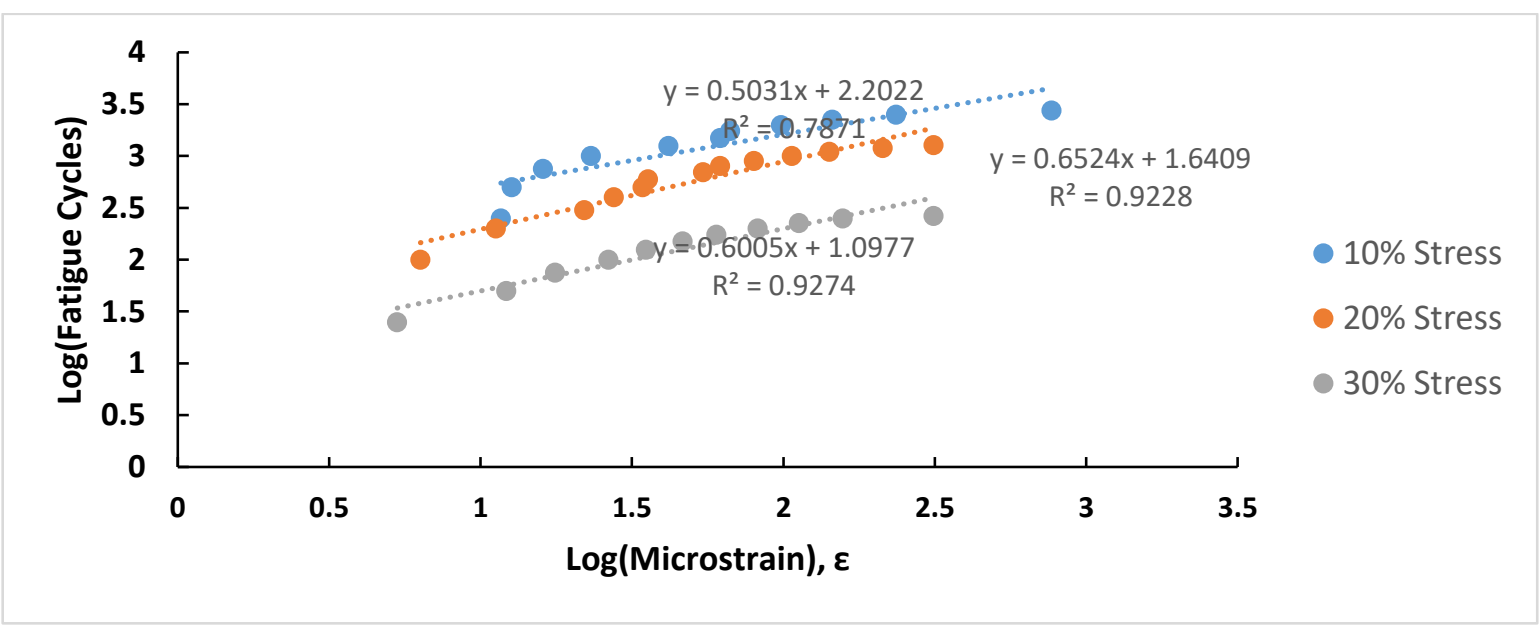

Figure 4: $\log -\log$ plot of Fatigue Cycles vs Micro strain for conventional SMA mix at $45^{\circ} \mathrm{C}$

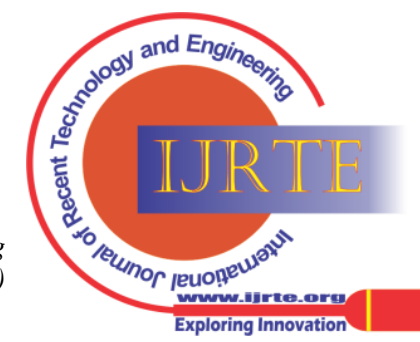


Evaluation of Fatigue Potential for Crumb Rubber Modified Bitumen in Stone Mastic Asphalt Mixes

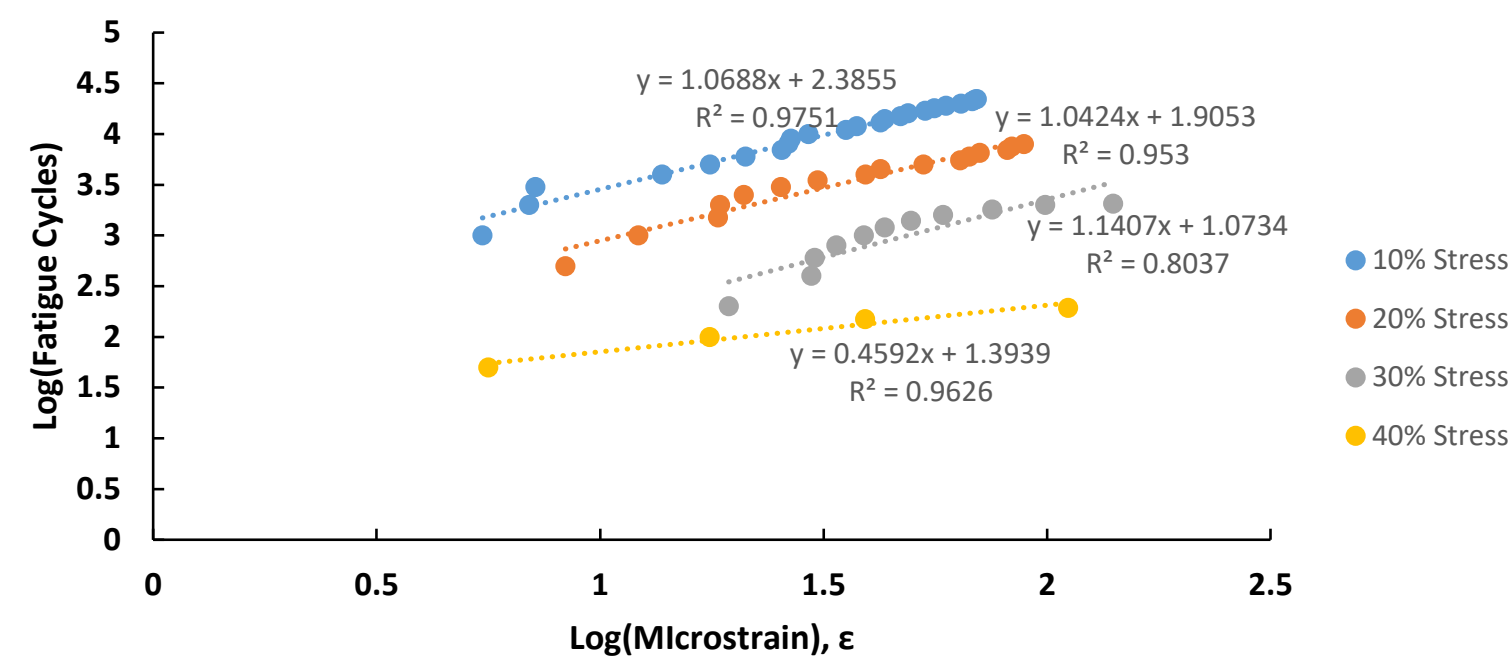

Figure 5: $\log -\log$ plot of Fatigue Cycles vs Micro strain for SMA mix with $40 \%$ RAP replacement at $25^{\circ} \mathrm{C}$

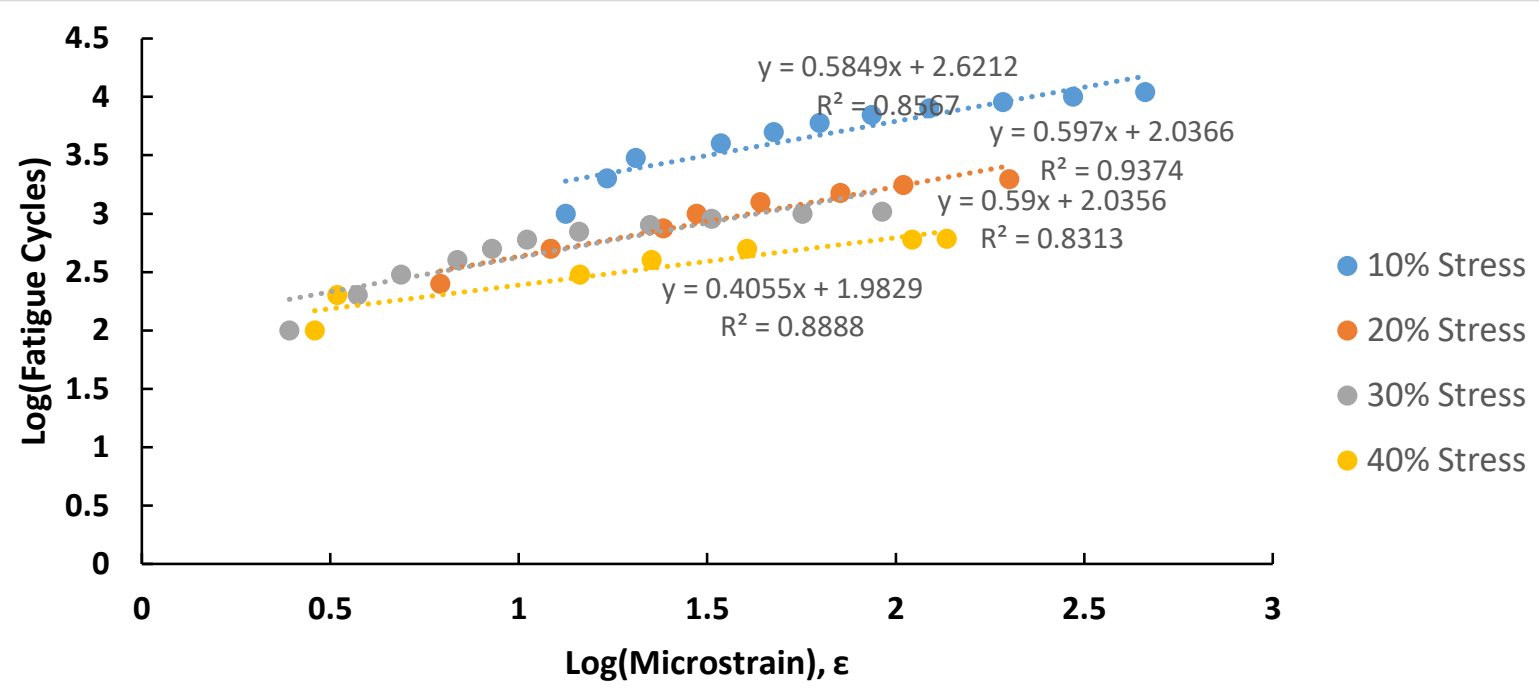

Figure 6: $\log -\log$ plot of Fatigue Cycles vs Micro strain for SMA mix with $40 \%$ RAP replacement at $35^{\circ} \mathrm{C}$

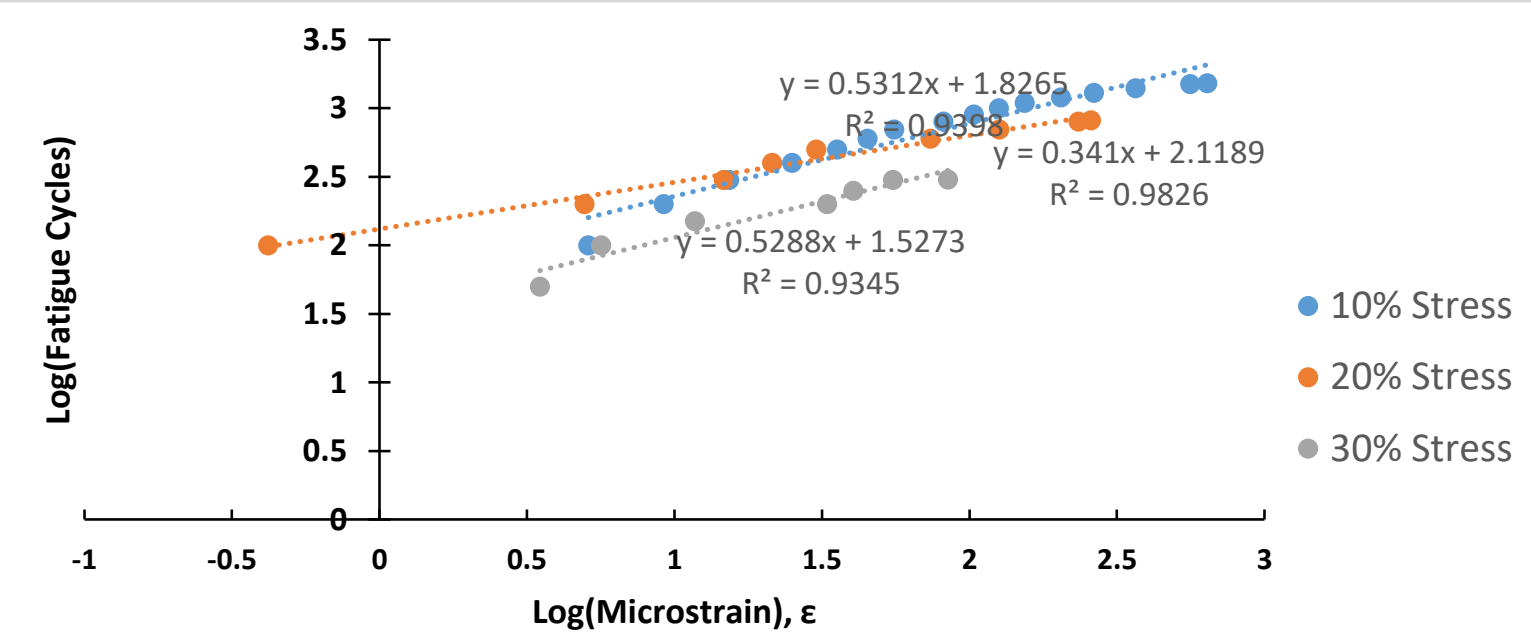

Figure 7: $\log -\log$ plot of Fatigue Cycles vs Micro strain for SMA mix with $40 \%$ RAP replacement at $45^{\circ} \mathrm{C}$

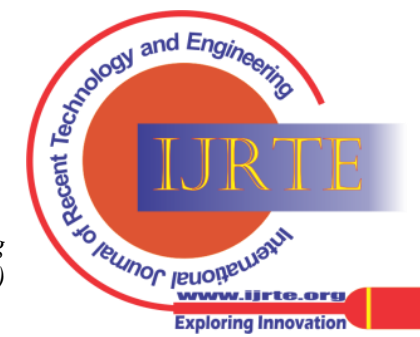




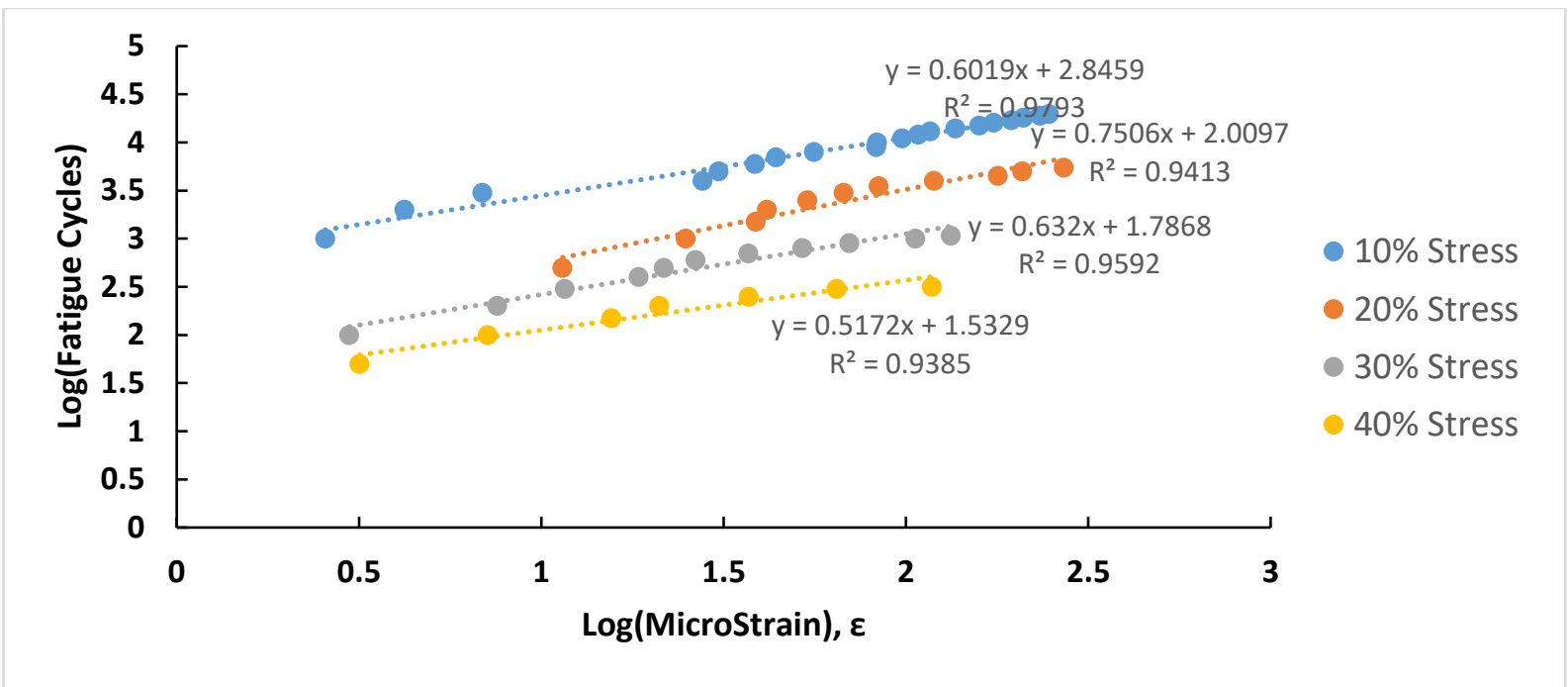

Figure 8: Log - Log plot of Fatigue Cycles vs Micro strain for SMA mix with 70\% RAP replacement and $25 \%$ WEO at $25^{\circ} \mathrm{C}$

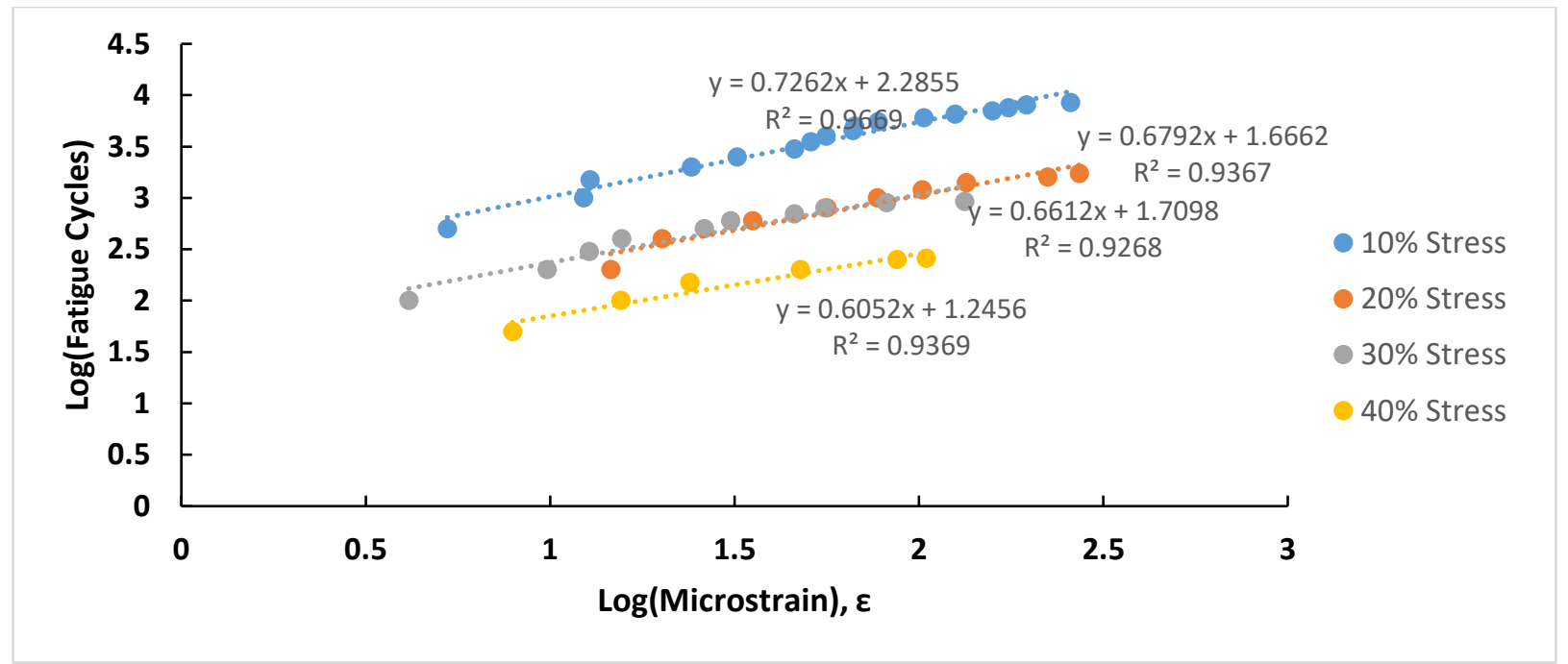

Figure 9: Log - Log plot of Fatigue Cycles vs Micro strain for SMA mix with 70\% RAP replacement and $25 \%$ WEO at $35^{\circ} \mathrm{C}$

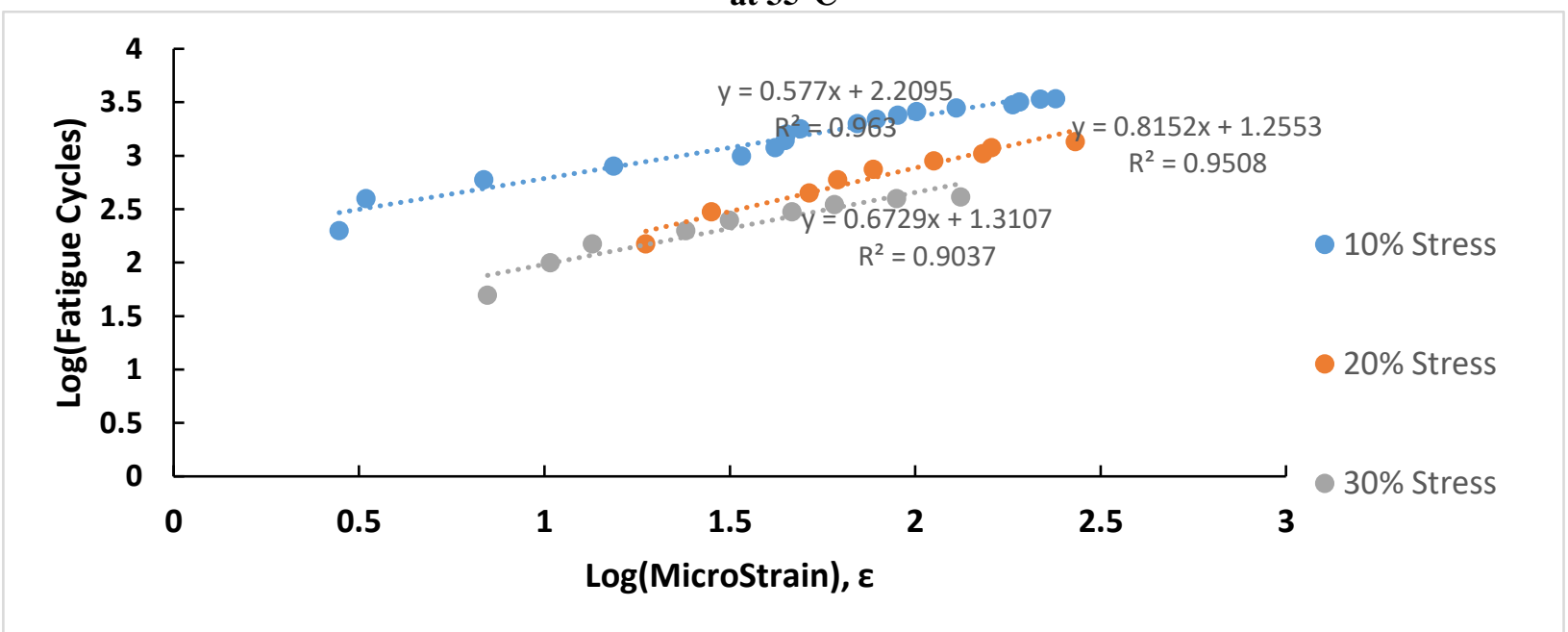

Figure 10: Log - Log plot of Fatigue Cycles vs Micro strain for SMA mix with $70 \%$ RAP replacement and $25 \%$ WEO at $45^{\circ} \mathrm{C}$

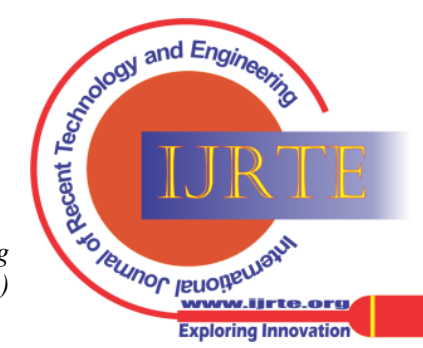


Evaluation of Fatigue Potential for Crumb Rubber Modified Bitumen in Stone Mastic Asphalt Mixes

Table-VI: Summary of regression equation between Fatigue cycles and Micro Strain from the ITFT test

\begin{tabular}{|c|c|c|c|c|c|c|}
\hline \multirow{2}{*}{ SMA Mix } & \multirow{2}{*}{ Temperature, ${ }^{\circ} \mathrm{C}$} & \multirow{2}{*}{ Stress levels, \% } & \multicolumn{4}{|c|}{$\log N_{\mathrm{f}}=\log \mathbf{k}_{1}+\mathbf{k}_{2} \log \varepsilon$} or $\left\{\mathbf{N}_{\mathrm{f}}=\mathbf{k}_{1}(\varepsilon)^{\wedge} \mathbf{k}_{2}\right\}$ \\
\hline & & & $\log _{1}$ & $\mathbf{k}_{1}$ & $\mathbf{k}_{2}$ & $\mathbf{R}^{2}$ \\
\hline \multirow{11}{*}{$\begin{array}{l}\text { Conventional } \\
\text { Mix }\end{array}$} & \multirow{4}{*}{25} & 10 & 2.1893 & 154.632 & 0.7101 & 0.9189 \\
\hline & & 20 & 1.5261 & 33.5815 & 0.843 & 0.8713 \\
\hline & & 30 & 1.5693 & 37.0937 & 0.7822 & 0.9371 \\
\hline & & 40 & 1.1213 & 13.2221 & 0.8032 & 0.8597 \\
\hline & \multirow{4}{*}{35} & 10 & 1.9225 & 83.6566 & 0.6366 & 0.8817 \\
\hline & & 20 & 1.4466 & 27.964 & 0.7388 & 0.8469 \\
\hline & & 30 & 1.0876 & 12.2349 & 0.781 & 0.879 \\
\hline & & 40 & 1.2146 & 16.3908 & 0.7077 & 0.9052 \\
\hline & \multirow{3}{*}{45} & 10 & 2.2022 & 159.294 & 0.5031 & 0.7871 \\
\hline & & 20 & 1.6409 & 43.7421 & 0.6524 & 0.9228 \\
\hline & & 30 & 1.0977 & 12.5228 & 0.6005 & 0.9274 \\
\hline \multirow{7}{*}{$\begin{array}{l}\text { 40\% RAP SMA } \\
\text { mix }\end{array}$} & \multirow{4}{*}{25} & 10 & 2.3855 & 242.941 & 1.0688 & 0.9751 \\
\hline & & 20 & 1.9053 & 80.4081 & 1.0424 & 0.953 \\
\hline & & 30 & 1.0734 & 11.8413 & 1.1407 & 0.8037 \\
\hline & & 40 & 1.3939 & 24.7685 & 0.4592 & 0.9626 \\
\hline & & 10 & 2.6212 & 418.023 & 0.5849 & 0.8567 \\
\hline & & 20 & 2.0366 & 108.793 & 0.597 & 0.9374 \\
\hline & (5) & 30 & 2.0356 & 108.543 & 0.59 & 0.8313 \\
\hline \multirow{4}{*}{$\begin{array}{l}\text { 40\% RAP SMA } \\
\text { mix }\end{array}$} & & 40 & 1.9829 & 96.1391 & 0.4055 & 0.8888 \\
\hline & \multirow{3}{*}{45} & 10 & 1.8265 & 67.0656 & 0.5312 & 0.82 \\
\hline & & 20 & 2.1189 & 131.492 & 0.341 & 0.9826 \\
\hline & & 30 & 1.5273 & 33.6744 & 0.5288 & 0.9345 \\
\hline \multirow{11}{*}{$\begin{array}{l}70 \% \text { RAP + } 25 \% \\
\text { WEO SMA Mix }\end{array}$} & \multirow{4}{*}{25} & 10 & 2.8459 & 701.294 & 0.6019 & 0.9793 \\
\hline & & 20 & 2.0097 & 102.259 & 0.7506 & 0.9413 \\
\hline & & 30 & 1.7868 & 61.2068 & 0.632 & 0.9592 \\
\hline & & 40 & 1.5329 & 34.1114 & 0.5172 & 0.9385 \\
\hline & \multirow{4}{*}{35} & 10 & 2.2855 & 192.975 & 0.7262 & 0.9669 \\
\hline & & 20 & 1.6662 & 46.366 & 0.6792 & 0.9367 \\
\hline & & 30 & 1.7098 & 51.2625 & 0.6612 & 0.9268 \\
\hline & & 40 & 1.2456 & 17.6035 & 0.6052 & 0.9369 \\
\hline & \multirow{3}{*}{45} & 10 & 2.2095 & 161.994 & 0.577 & 0.963 \\
\hline & & 20 & 1.2553 & 18.0011 & 0.8152 & 0.9508 \\
\hline & & 30 & 1.3107 & 20.4503 & 0.6729 & 0.9037 \\
\hline
\end{tabular}

Fig. 11 shows the no. of fatigue cycle at which the specimen failed for three SMA mixes at various temperature and Stress levels. From the Figure, it can be noticed that the SMA mix with RAP appears to be most resistant to fatigue followed by SMA mix replaced with RAP \& WEO and then by conventional SMA mix. At higher temperature and low stresses, the conventional mix appear to perform better than the mix with RAP without rejuvenators. The sample with rejuvenator performs slightly better than the conventional mix. At higher stresses, irrespective of temperature, the conventional SMA mix performs better than both the RAP replaced samples.

Fig. 12 shows the micro strain (Horizontal tensile Strain) at which the specimen failed for three SMA mixes at various temperature and Stress levels.

Blue Eyes Intelligence Engineering and Sciences Publication (BEIESP)

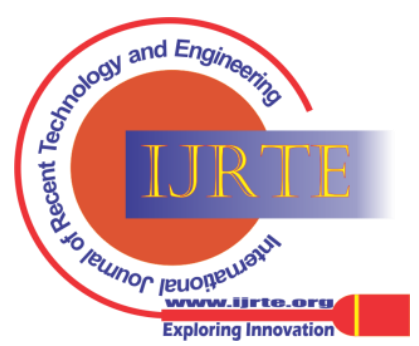


It can be seen that at lower stress levels (10\% and 20\%), substantial reduction in strain at failure can be observed by using SMA mix RAP replacement. The effect is more pronounced in SMA - RAP mix without rejuvenators than with rejuvenators. As the stress level increases, this effect becomes less and less visible and at about $40 \%$ stress all sample exhibit similar failure strain with the conventional mix producing slightly higher strain.

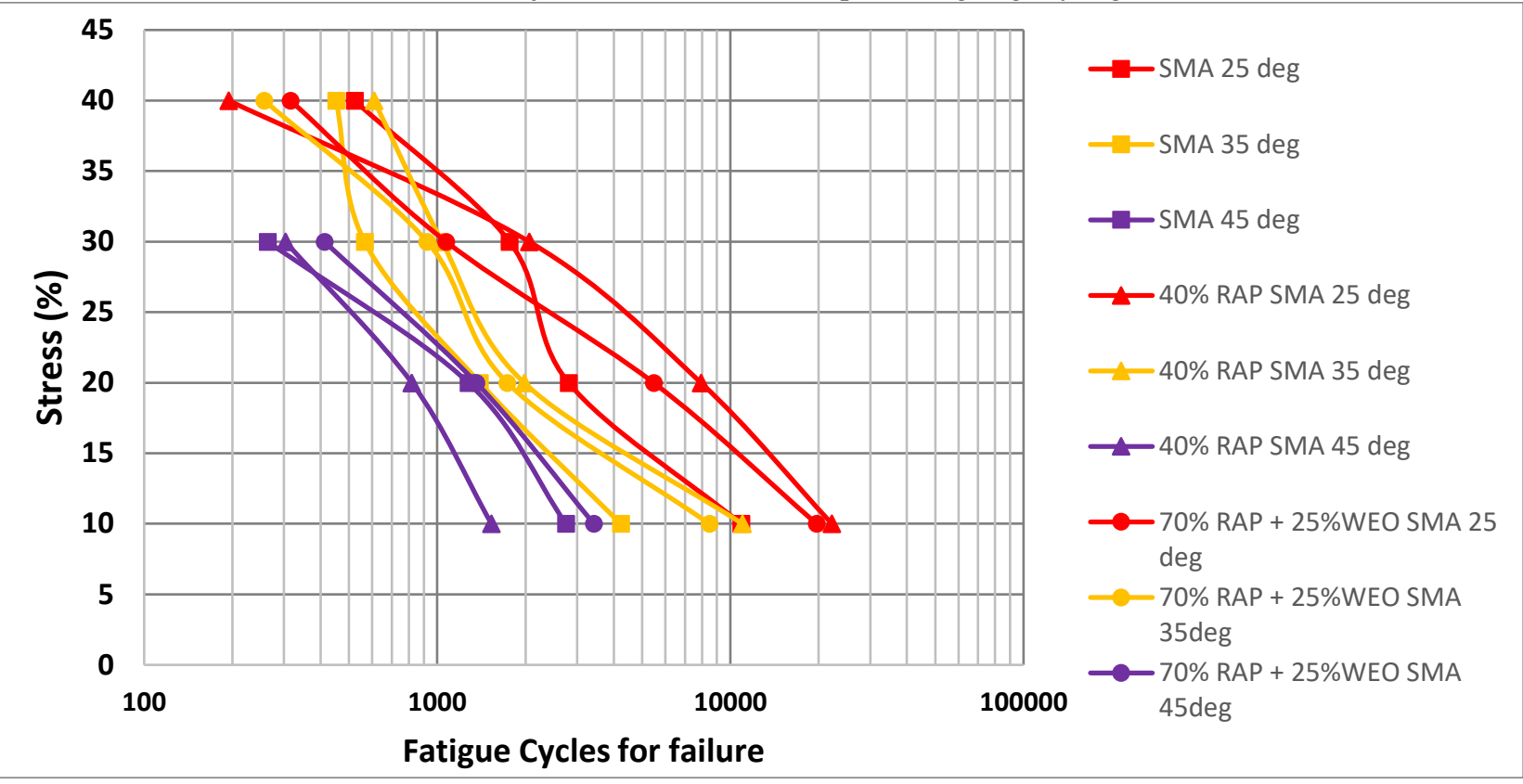

Fig. 11: Fatigue Cycle for failure vs Stress level at various temperature for the three optimum SMA mixes

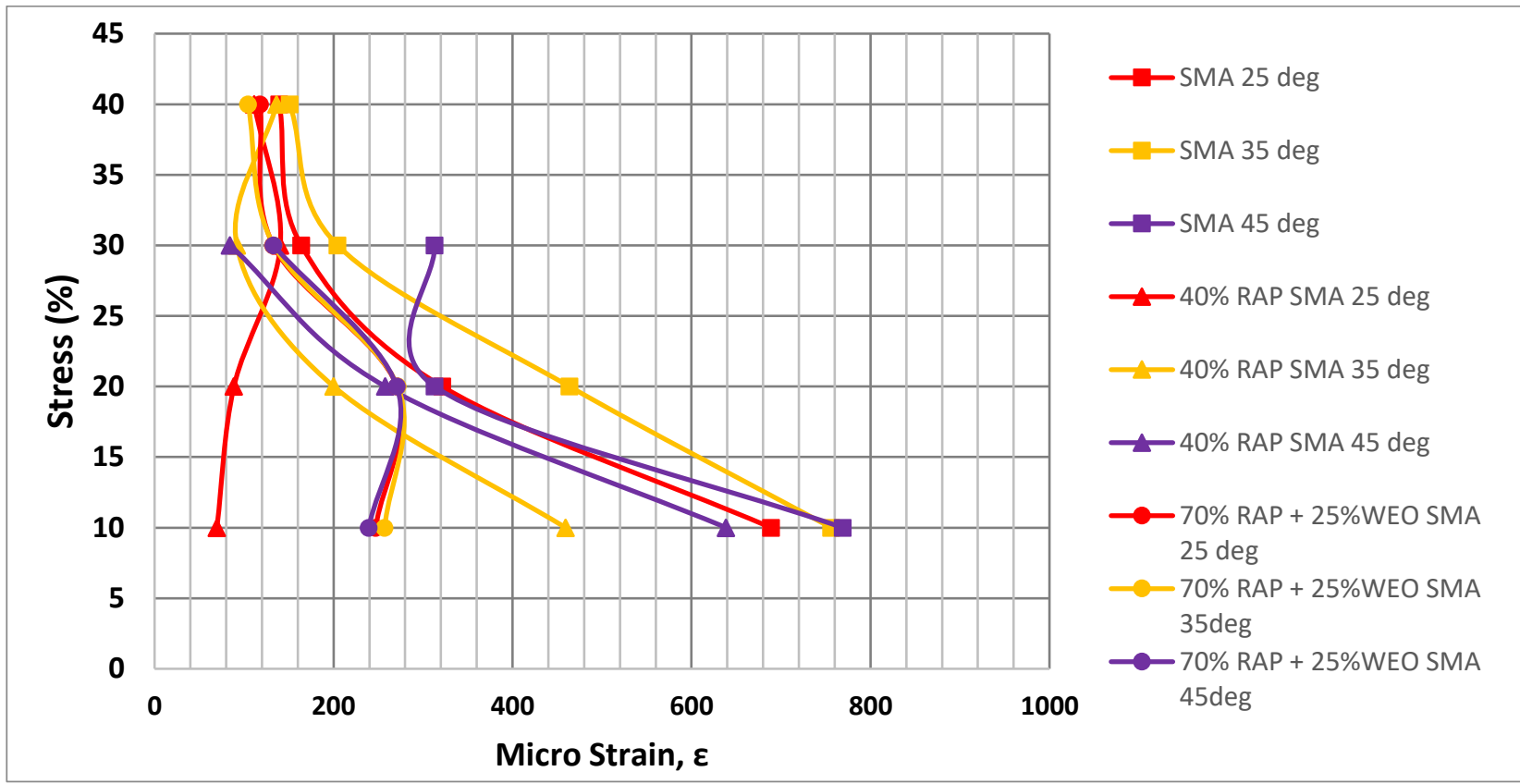

Fig. 12: Micro strain at failure vs Stress level at various temperature for the three optimum SMA mixes

\section{Resilient Modulus}

Fig. 13 - 21 shows a typical variation of resilient modulus with number of fatigue cycles. Table 7 provides the summary of regression equation between Fatigue cycles and resilient modulus. The resilient modulus of the sample mix goes on decreasing with the increase in the fatigue cycles and stress. The $\mathrm{y}$ - intercept $\left(\log _{3}\right)$ of regression equation represents the number of fatigue cycle at failure for unit resilient modulus. It can be observed from the figures that at lower room temperature $\left(25^{\circ} \mathrm{C}\right)$ and low stress levels, the resilient modulus of RAP replaced SMA mix without
WEO significantly increases the resilient modulus over conventional SMA mix. At intermediate and higher temperatures $\left(35^{\circ} \mathrm{C}\right.$ and $\left.45^{\circ} \mathrm{C}\right)$, conventional SMA mix appears to have higher resilient modulus than RAP replaced optimum mix with and without rejuvenators. The overview of the results show that even the reduction in resilient modulus for most of the conditions is within $5 \%$. It can be further noted that with the increase in stresses, irrespective of temperature, the resilient modulus decreases.

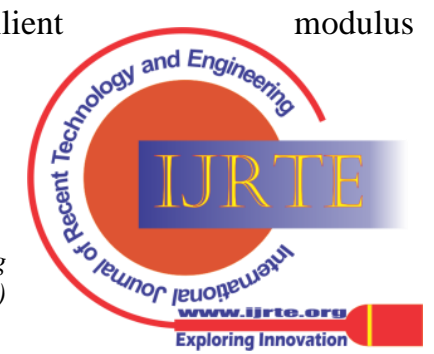




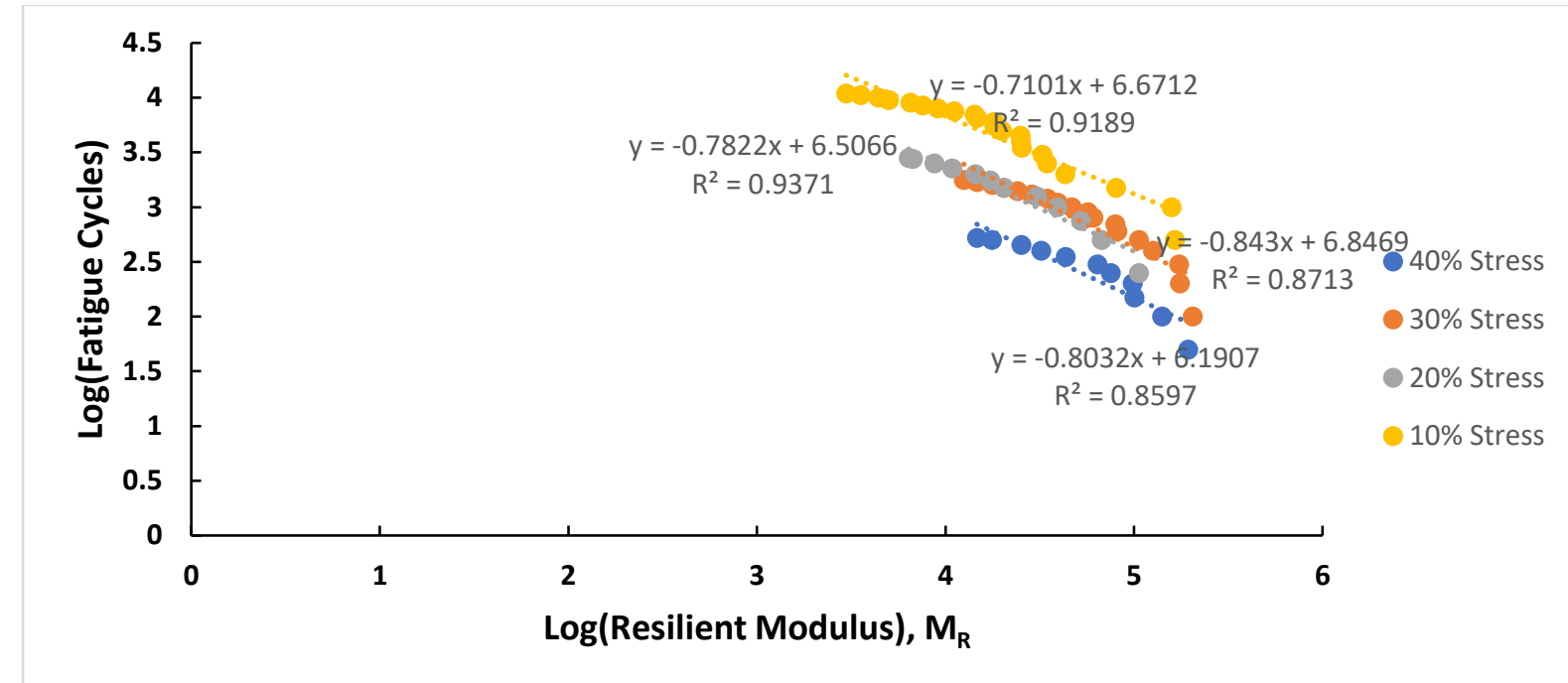

Figure 13: Log - Log plot of Fatigue cycles V/s Resilient Modulus for conventional SMA at $25^{\circ} \mathrm{C}$

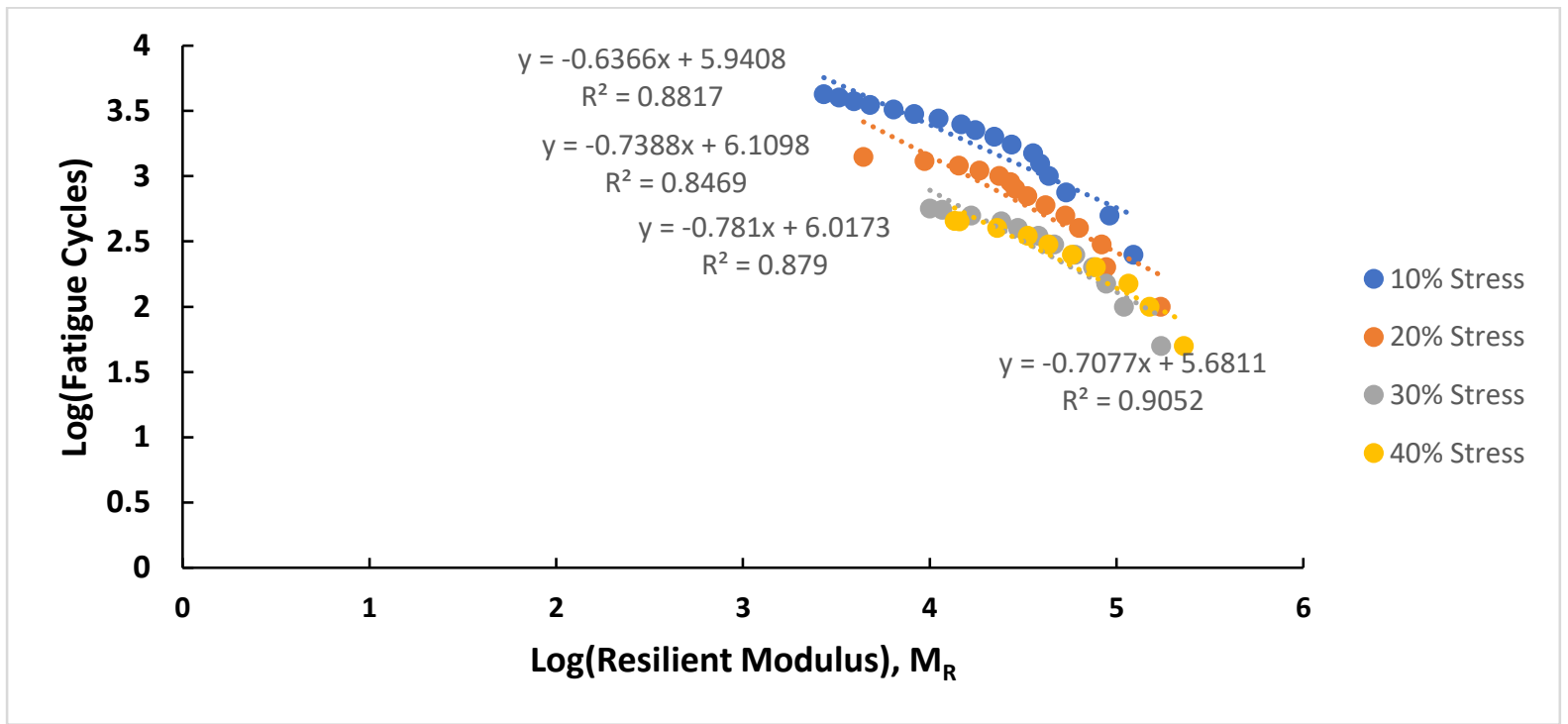

Figure 14: Log - Log plot of Fatigue cycles V/s Resilient Modulus for conventional SMA at $35^{\circ} \mathrm{C}$

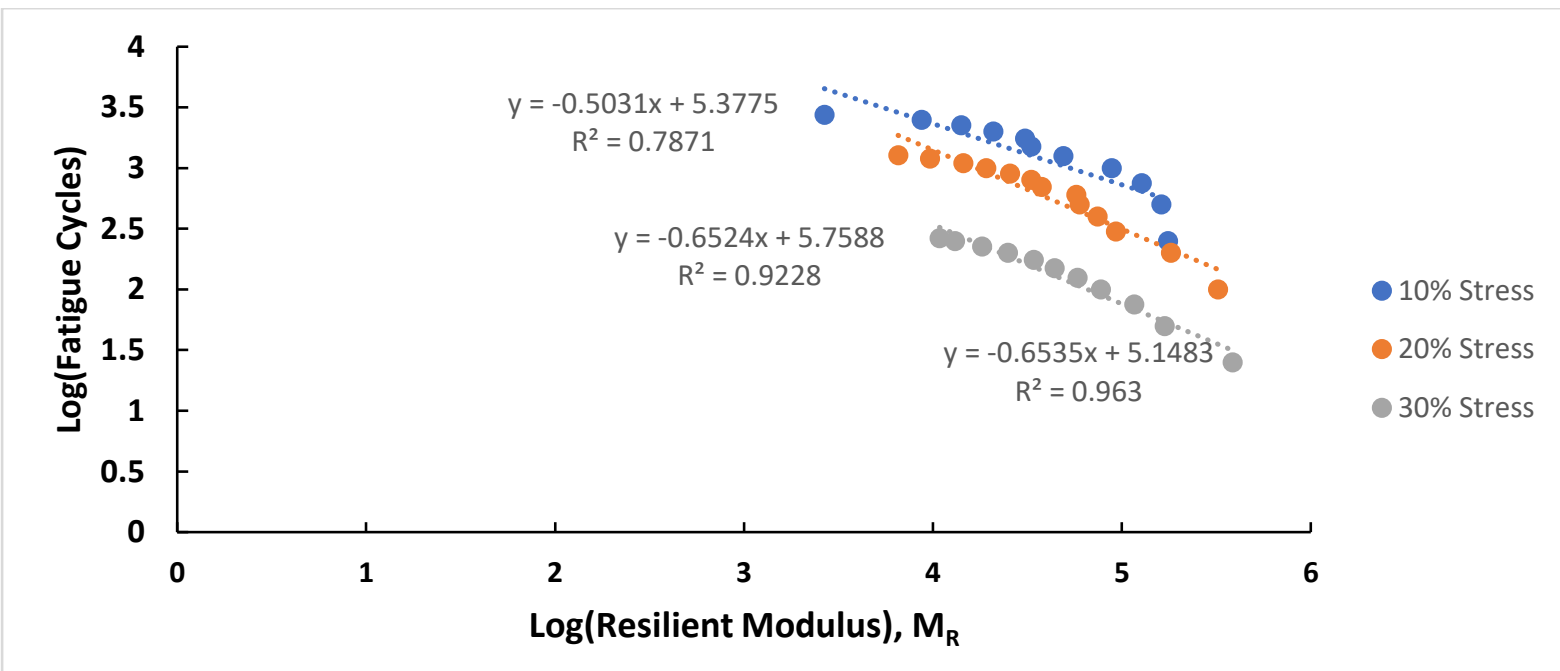

Figure 15: Log - Log plot of Fatigue cycles V/s Resilient Modulus for conventional SMA at $45^{\circ} \mathrm{C}$

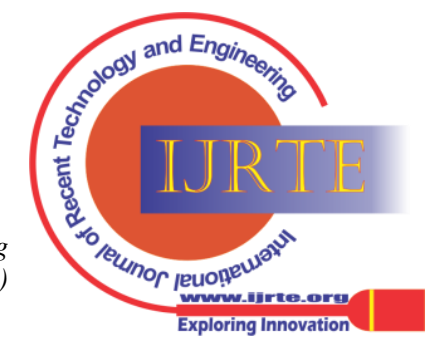




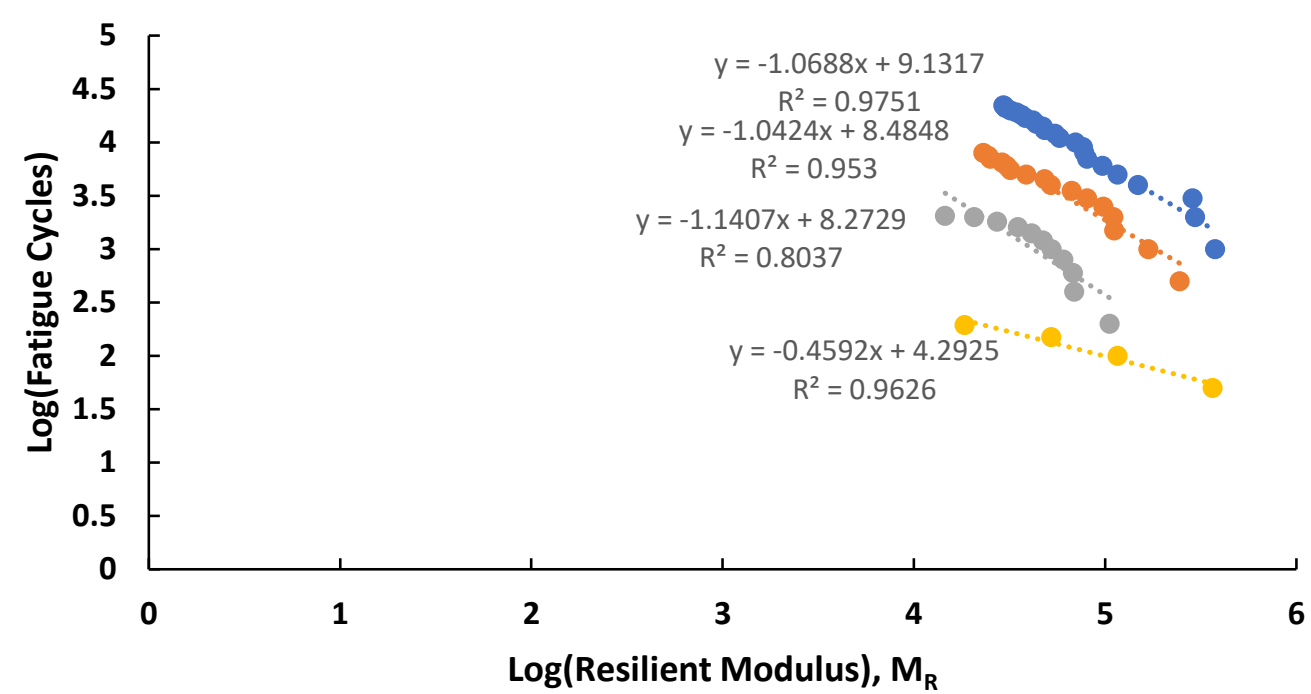

$10 \%$ Stress

$20 \%$ Stress

$30 \%$ Stress

$40 \%$ Stress

Figure 16: Log - Log plot of Fatigue cycles V/s Resilient Modulus for SMA with $40 \%$ RAP replacement at $25^{\circ} \mathrm{C}$

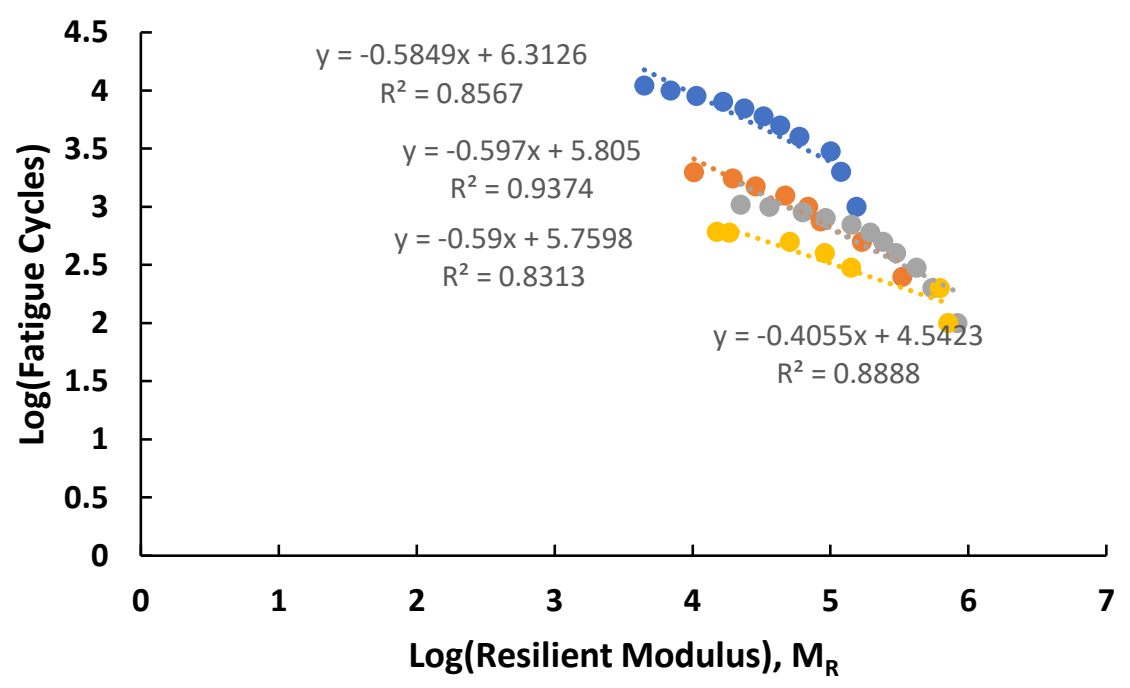

Figure 17: Log - Log plot of Fatigue cycles V/s Resilient Modulus for SMA with $40 \%$ RAP replacement at $35^{\circ} \mathrm{C}$

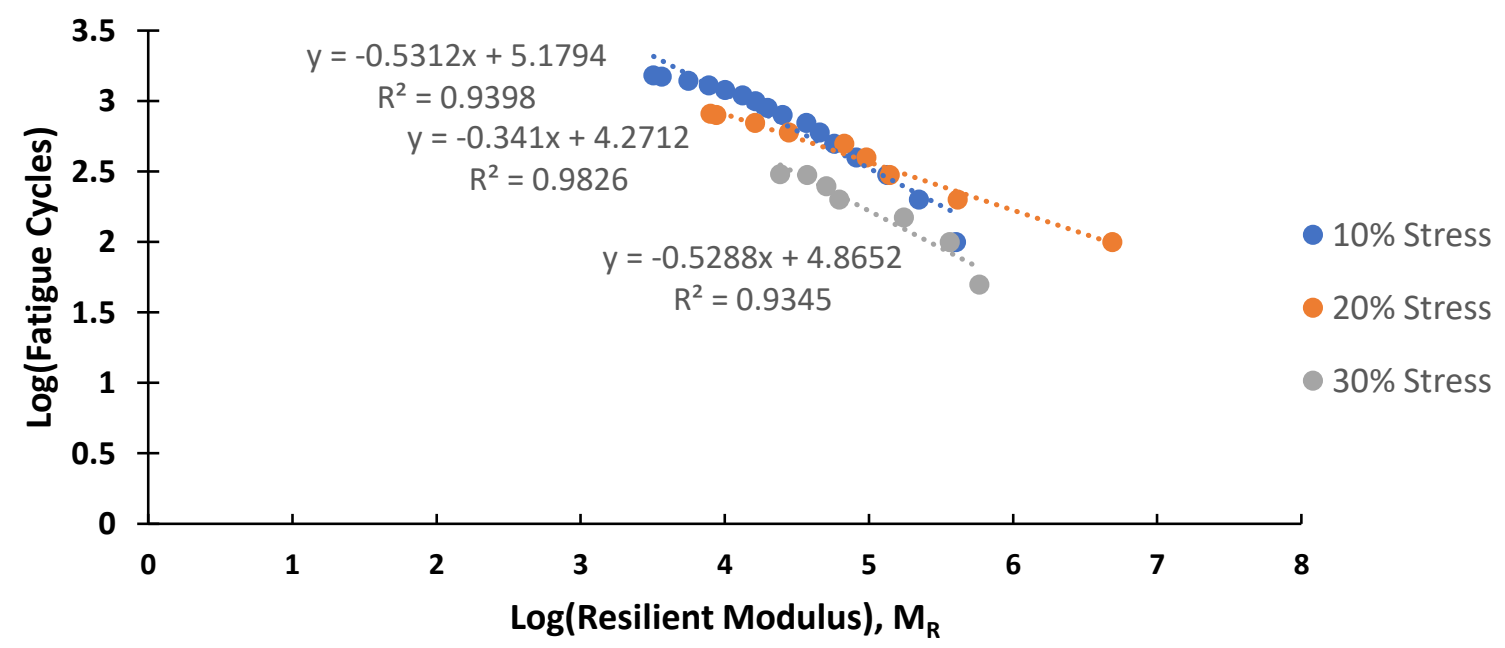

Figure 18: Log - Log plot of Fatigue cycles V/s Resilient Modulus for SMA with $40 \%$ RAP replacement $45^{\circ} \mathrm{C}$

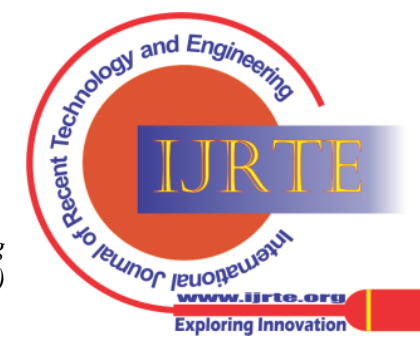




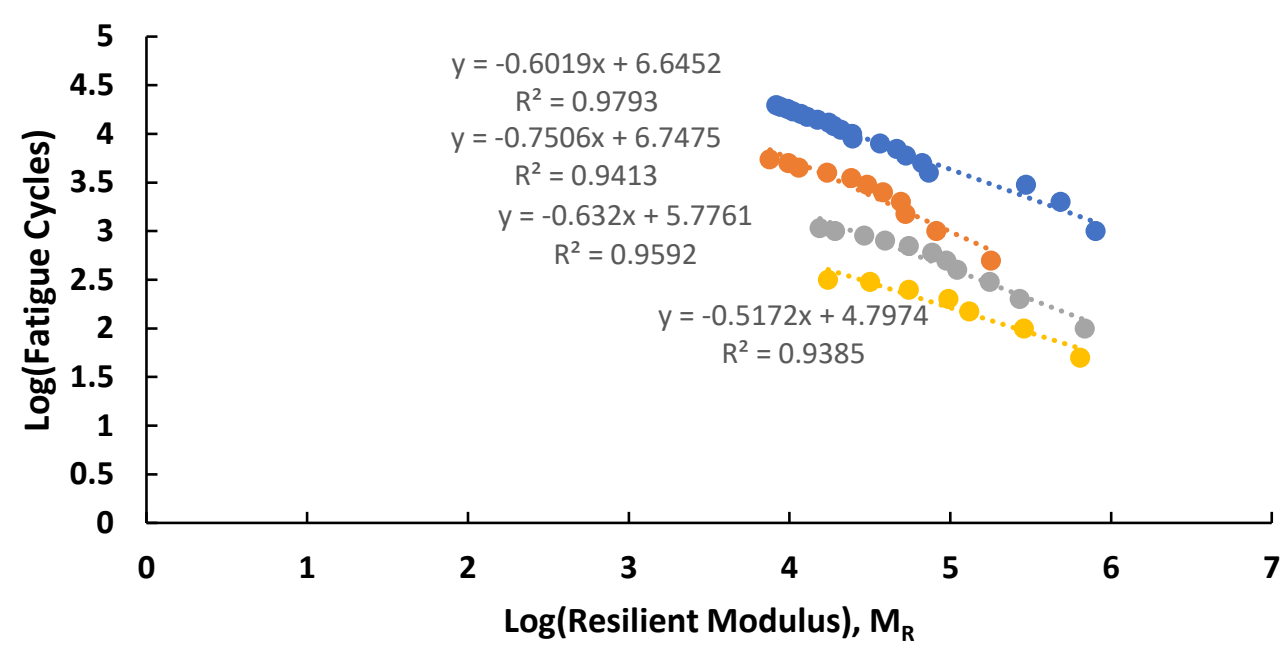

- $10 \%$ Stress

- $20 \%$ Stress

$30 \%$ Stress

$40 \%$ Stress

Figure 19: Log - Log plot of Fatigue cycles V/s Resilient Modulus for SMA mix with 70\% RAP replacement and 25\% WEO at $25^{\circ} \mathrm{C}$

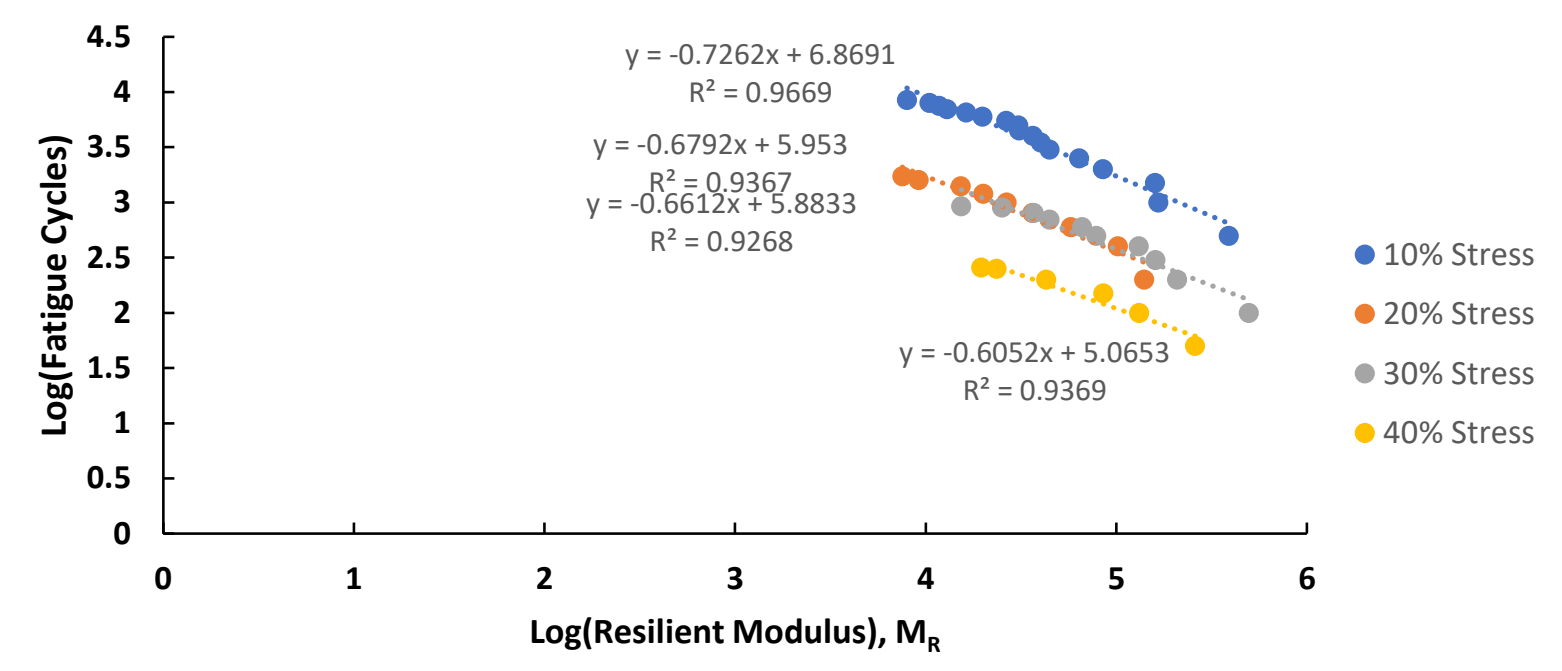

Figure 20: Log - Log plot of Fatigue cycles V/s Resilient Modulus for SMA mix with 70\% RAP replacement and 25\% WEO $35^{\circ} \mathrm{C}$

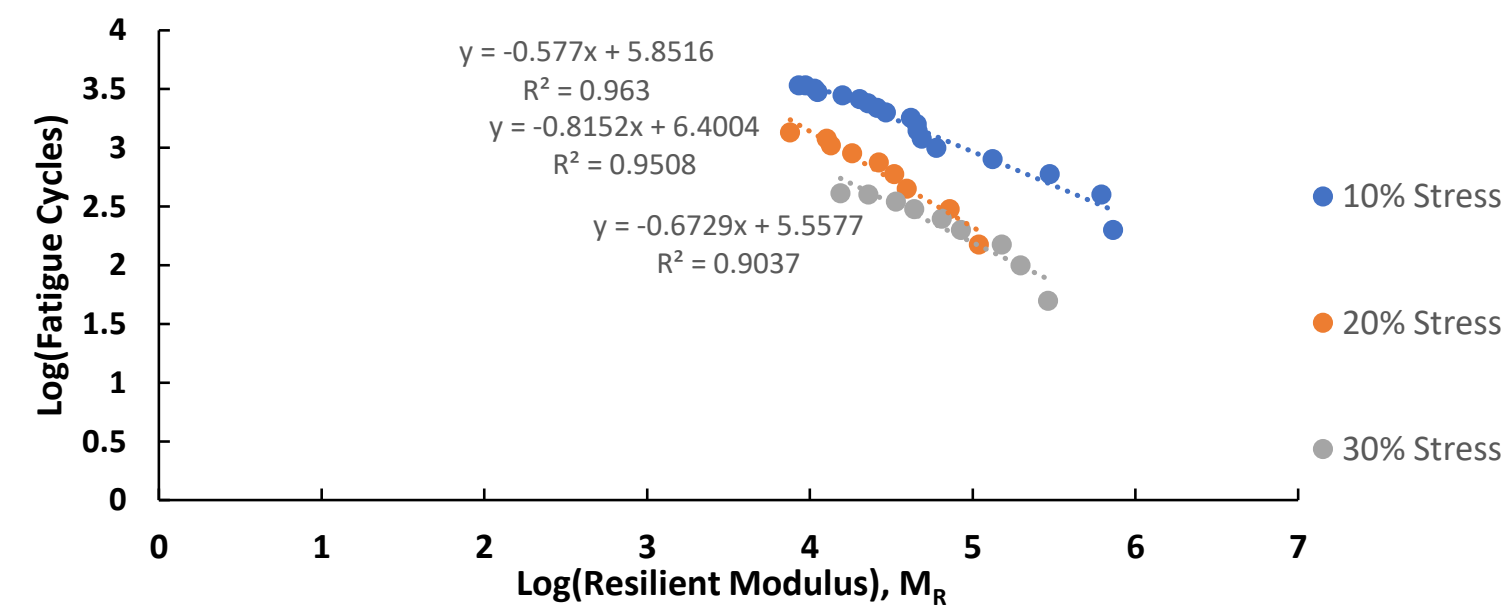

Figure 21: Log - Log plot of Fatigue cycles V/s Resilient Modulus for SMA mix with 70\% RAP replacement and 25\% WEO $45^{\circ} \mathrm{C}$

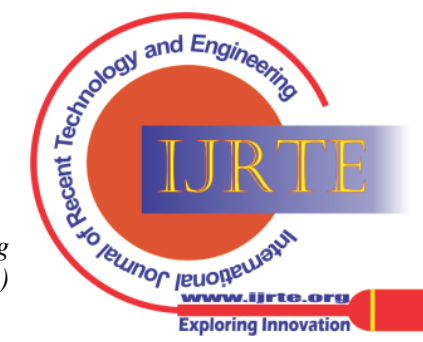


Table-VII: Summary of regression equation between Fatigue cycles and Resilient Modulus from the ITFT test

\begin{tabular}{|c|c|c|c|c|c|c|}
\hline \multirow{2}{*}{ SMA Mix } & \multirow{2}{*}{ Temperature, ${ }^{\circ} \mathrm{C}$} & \multirow{2}{*}{$\begin{array}{c}\text { Stress } \\
\text { levels, \% }\end{array}$} & \multicolumn{4}{|c|}{$N_{f}=k_{3}\left(M_{R}\right)^{\wedge} k_{4}$} or $\left\{\log N_{f}=\log k_{3}+k_{4} \log M_{R}\right\}$ \\
\hline & & & $\operatorname{Logk}_{3}$ & $\mathbf{K}_{3}$ & $\mathbf{K}_{4}$ & $\mathbf{R}^{2}$ \\
\hline \multirow{11}{*}{ Conventional Mix } & \multirow{4}{*}{25} & 10 & 6.6712 & 4690293 & -0.7101 & 0.9189 \\
\hline & & 20 & 6.5066 & 3210702 & -0.7822 & 0.9371 \\
\hline & & 30 & 6.8469 & 7029105 & -0.843 & 0.8713 \\
\hline & & 40 & 6.1907 & 1551315 & -0.8032 & 0.8597 \\
\hline & \multirow{4}{*}{35} & 10 & 5.9408 & 872569 & -0.6366 & 0.8817 \\
\hline & & 20 & 6.1098 & 1287656 & -0.7388 & 0.8469 \\
\hline & & 30 & 6.0173 & 1040639 & -0.781 & 0.879 \\
\hline & & 40 & 5.6811 & 479844 & -0.7077 & 0.9052 \\
\hline & \multirow{3}{*}{45} & 10 & 5.3775 & 238506 & -0.5031 & 0.7871 \\
\hline & & 20 & 5.7588 & 573852 & -0.6524 & 0.9228 \\
\hline & & 30 & 5.1483 & 140702 & -0.6535 & 0.963 \\
\hline \multirow{11}{*}{ 40\% RAP SMA mix } & \multirow{4}{*}{25} & 10 & 9.1317 & $1.4 \mathrm{E}+09$ & -1.0688 & 0.9751 \\
\hline & & 20 & 8.4848 & $3.1 \mathrm{E}+08$ & -1.0424 & 0.953 \\
\hline & & 30 & 8.2729 & $1.9 \mathrm{E}+08$ & -1.1407 & 0.8037 \\
\hline & & 40 & 4.2925 & 19611 & -0.4592 & 0.9626 \\
\hline & \multirow{4}{*}{35} & 10 & 6.3126 & 2053998 & -0.5849 & 0.8567 \\
\hline & & 20 & 5.805 & 638263 & -0.597 & 0.9374 \\
\hline & & 30 & 5.7598 & 575175 & -0.59 & 0.8313 \\
\hline & & 40 & 4.5423 & 34857.8 & -0.4055 & 0.8888 \\
\hline & \multirow{3}{*}{45} & 10 & 5.1794 & 151147 & -0.5312 & 0.9398 \\
\hline & & 20 & 4.2712 & 18672.4 & -0.341 & 0.9826 \\
\hline & & 30 & 4.8652 & 73316.2 & -0.5288 & 0.9345 \\
\hline \multirow{11}{*}{$\begin{array}{c}70 \% \text { RAP + } 25 \% \text { WEO } \\
\text { SMA MIX }\end{array}$} & \multirow{4}{*}{25} & 10 & 6.6452 & 4417738 & -0.6019 & 0.9793 \\
\hline & & 20 & 6.7475 & 5591135 & -0.7506 & 0.9413 \\
\hline & & 30 & 5.7761 & 597173 & -0.632 & 0.9592 \\
\hline & & 40 & 4.7974 & 62719.1 & -0.5172 & 0.9385 \\
\hline & \multirow{4}{*}{35} & 10 & 6.8691 & 7397756 & -0.7262 & 0.9669 \\
\hline & & 20 & 5.953 & 897429 & -0.6792 & 0.9367 \\
\hline & & 30 & 5.8833 & 764364 & -0.6612 & 0.9268 \\
\hline & & 40 & 5.0653 & 116225 & -0.6052 & 0.9369 \\
\hline & \multirow{3}{*}{45} & 10 & 5.8516 & 710559 & -0.577 & 0.963 \\
\hline & & 20 & 6.4004 & 2514201 & -0.8152 & 0.9508 \\
\hline & & 30 & 5.5577 & 361160 & -0.6729 & 0.9037 \\
\hline
\end{tabular}

\section{CONCLUSION}

- The Marshall stability of the conventional SMA mix is enhanced significantly by RAP replacement with or without rejuvenators. The RAP replaced SMA mix without rejuvenators offers better stability than those with rejuvenators.

- Tensile Strength Ratio and in turn the resistance to moisture susceptibility of SMA mix with RAP offers is higher than SMA mix with RAP and rejuvenator. Both the RAP replaced samples offer better moisture resistance than conventional SMA mix.

- At lower temperature (i.e., $25^{\circ} \mathrm{C}$ and $35^{\circ} \mathrm{C}$ ), and low stress level (i.e., $10 \%$ and $20 \%$ ), the SMA mix with RAP appears to be most resistant to fatigue followed by SMA mix replaced with RAP \& WEO and then by conventional SMA mix. At higher temperature (i.e., $45^{\circ} \mathrm{C}$ ) and low stresses, the conventional SMA mixture appears to be more stable than the mix with RAP 
- With the increase in fatigue cycles, the resilient modulus decreases considerable. With the increase in stresses, irrespective of temperature, the resilient modulus decreases.

- At lower temperature $\left(25^{\circ} \mathrm{C}\right)$, the resilient modulus of conventional SMA mix is considerably improved by the addition of RAP and rejuvenators. At intermediate and higher temperatures $\left(35^{\circ} \mathrm{C}\right.$ and $\left.45^{\circ} \mathrm{C}\right)$, the conventional SMA offers a higher resilient modulus than with RAP and rejuvenators.

\section{REFERENCES}

1. B. Huang, G. Li, D. Vukosavljevic, X. Shu, and B. K. Egan, "Laboratory Investigation of Mixing Hot-Mix Asphalt with Reclaimed Asphalt Pavement," Transp. Res. Rec. J. Transp. Res. Board, vol. 1929, no. 1, pp. 37-45, 2005, doi: 10.1177/0361198105192900105.

2. J. Shen, S. Amirkhanian, and J. Aune Miller, "Effects of rejuvenating agents on superpave mixtures containing reclaimed asphalt pavement," J. Mater. Civ. Eng., vol. 19, no. 5, pp. 376-384, 2007, doi: 10.1061/(ASCE)0899-1561(2007)19:5(376).

3. F. Xiao, S. Amirkhanian, and C. H. Juang, "Rutting resistance of rubberized asphalt concrete pavements containing reclaimed asphalt pavement mixtures," J. Mater. Civ. Eng., vol. 19, no. 6, pp. 475-483, 2007, doi: 10.1061/(ASCE)0899-1561(2007)19:6(475).

4. F. Xiao, S. N. Amirkhanian, J. Shen, and B. Putman, "Influences of crumb rubber size and type on reclaimed asphalt pavement (RAP) mixtures," Constr. Build. Mater., vol. 23, no. 2, pp. 1028-1034, 2009, doi: 10.1016/j.conbuildmat.2008.05.002.

5. B. V. Kök and H. Colak, "Laboratory comparison of the crumbrubber and SBS modified bitumen and hot mix asphalt," Constr. Build. Mater., vol. 25, no. 8, pp. 3204-3212, 2011, doi: 10.1016/j.conbuildmat.2011.03.005.

6. F. Xiao and S. N. Amirkhanian, "Resilient modulus behavior of rubberized asphalt concrete mixtures containing reclaimed asphalt pavement," Road Mater. Pavement Des., vol. 9, no. 4, pp. 633-649, 2008, doi: 10.3166/rmpd.9.633-649.

7. H. Wang, Z. Dang, L. Li, and Z. You, "Analysis on fatigue crack growth laws for crumb rubber modified (CRM) asphalt mixture,' Constr. Build. Mater., vol. 47, pp. 1342-1349, 2013, doi: 10.1016/j.conbuildmat.2013.06.014.

8. A. Talati and V. Talati, "Study of Stone Matrix Asphalt For The Flexible Pavement," Int. J. Eng. Dev. Res., vol. 2, no. 1, pp. 789 792, 2014, [Online]. Available: www.ijedr.org.

9. M. Zaumanis, R. B. Mallick, L. Poulikakos, and R. Frank, "Influence of six rejuvenators on the performance properties of Reclaimed Asphalt Pavement (RAP) binder and 100\% recycled asphalt mixtures," Comput. Chem. Eng., vol. 71, no. July 2015, pp. 538 550, 2014, doi: 10.1016/j.conbuildmat.2014.08.073.

10. N. Tran, A. Taylor, P. Turner, C. Holmes, and L. Porot, "Effect of rejuvenator on performance characteristics of high RAP mixture," Asph. Paving Technol. Assoc. Asph. Paving Technol. Tech. Sess., vol. 85, pp. 283-313, 2016, doi: 10.1080/14680629.2015.1266757.

11. A. Ka Patel, S. Gupte, and N. B. Parmar, "Stone Matrix Asphalt (SMA) Mix Design Using Different Filler," vol. 3, no. 3, pp. 179182, 2016.

12. M. Zaumanis, R. Mallick, and R. Frank, "Evaluation of rejuvenator's effectiveness with conventional mix testing for 100\% reclaimed Asphalt pavement mixtures," Transp. Res. Rec., no. 2370, pp. 17-25, 2013, doi: 10.3141/2370-03.

13. M. Irfan, Y. Ali, S. Ahmed, and I. Hafeez, "Performance Evaluation of Crumb Rubber-Modified Asphalt Mixtures Based on Laboratory and Field Investigations," Arab. J. Sci. Eng., vol. 43, no. 4, pp. 1795-1806, 2018, doi: 10.1007/s13369-017-2729-2.

14. R. H. Ariyapijati, S. P. Hadiwardoyo, and R. J. Sumabrata, "Contributions crumb rubber in hot mix asphalt to the resilient modulus," AIP Conf. Proc., vol. 1855, 2017, doi: 10.1063/1.4985475.

15. G. Mazzoni, E. Bocci, and F. Canestrari, "Influence of rejuvenators on bitumen ageing in hot recycled asphalt mixtures," J. Traffic Transp. Eng. (English Ed., vol. 5, no. 3, pp. 157-168, 2018, doi: 10.1016/j.jtte.2018.01.001.

16. P. C. Shekar, B. H. Rajath, and J. S. Vishwas, "Experimenta investigation of Stone Mastic Asphalt by varying mix design," Int. Res. J. Eng. Technol., vol. 05, no. 05, pp. 300-305, 2018.

17. Y. Sun, C. Fang, D. Fan, J. Wang, and X. Yuan, "A Research on Fatigue Damage Constitutive Equation of Asphalt Mixture," Math. Probl. Eng., vol. 2018, 2018, doi: 10.1155/2018/3489082.

18. M. A. M. Al-bared and A. Marto, Evaluating the compaction behaviour of soft marine clay stabilized with two sizes of recycled crushed tiles, In: Pradhan B. (eds) GCEC 2017. GCEC 2017. Lecture Notes in Civil Engineering, vol 9. Springer, Singapore. Springer Singapore, 2019.

19. H. Li et al., "Laboratory and field investigation of the feasibility of crumb rubber waste application to improve the flexibility of antirutting performance of asphalt pavement," Materials (Basel)., vol 11, no. 9, 2018, doi: 10.3390/ma11091738.

20. C. Hanumantharao, T. Anil Pradhyumna, K. Durga Prasad, N. Naveenkumar, G. Shantha Kumar Reddy, and M. Hemanth Vardhan, "Crumb rubber modified bitumen and quarry dust in flexible pavements," Int. J. Recent Technol. Eng., vol. 8, no. 1, pp. 2868 2873, 2019

21. H. H. Joni, R. H. A. Al-Rubaee, and M. A. Al-zerkani, "Rejuvenation of aged asphalt binder extracted from reclaimed asphalt pavement using waste vegetable and engine oils," Case Stud Constr. Mater., vol. 11, p. e00279, 2019, doi: 10.1016/j.cscm.2019.e00279.

22. H. Wang, X. Liu, M. van de Ven, G. Lu, S. Erkens, and A. Skarpas, "Fatigue performance of long-term aged crumb rubber modified bitumen containing warm-mix additives," Constr. Build. Mater., vol. 239, p. 117824, 2020, doi: 10.1016/j.conbuildmat.2019.117824.

\section{AUTHOR'S PROFILE}

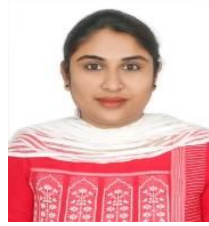

Anusha T M, is currently a Ph.D. Student of BMS College of Engineering in the Department of Civil Engineering, Bangalore-560019. Prior to this her recent appointment was at the PES University as an Assistant Professor in the Department of Civi Engineering. Anusha T M received her Master's degree in Transportation Engineering and Management from Siddaganga Institute of Technology, Karnataka. She also presented various research-based papers in the field of Pavement Materials and Construction at different journals and national and international conferences like At National Conference On Recent Advancements in Geotechnical engineering and At First International Conference on Materials science and manufacturing technology 2019

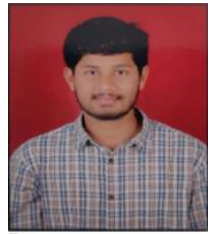

Sharath Kumar $\mathbf{M} \mathbf{D}$, is presently working as a (Public Works Department) PWD site Engineer a Public Works Department special division, Hassan, Karnataka. Prior to this he worked as planning Engineer in Public Works Department, Hassan. He received his Master's Degree in Transportation Engineering and Management from BMS College of Engineering in the Department of Civil Engineering, Bangalore-560019, and Karnataka, India. Sharath Kumar M D received his Bachelor in Engineering in Civil Engineering in Government College of Engineer, from Vivesvaraya Technological University, Belgaum, Karnataka, India. He is presently involved construction work such as construction of roads, bridges, buildings and irrigation canals.

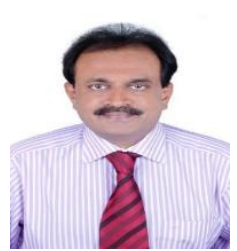

Dr H S Jagadeesh, is currently working as a Professor at the Department of Civil Engineering in BMS College of Engineering, Bangalore-560019. H S Jagadeesh received Doctor in Philosophy (Ph.D.) Civil Engineering in 2002 and Master's degree in Highway Engineering in 1991 from Bangalore University. He also worked as Dean of placement and Director of International co-operation division for BMS Educational trust for international collaborations. He also published various academic as well as research based papers in the field of Traffic Engineering and Pavement Materials and Construction in several journal like Indian Roads Congress (IRC), Transportation Research Board (TRB), and International Journal of Pavement Engineering Asphalt Technology.

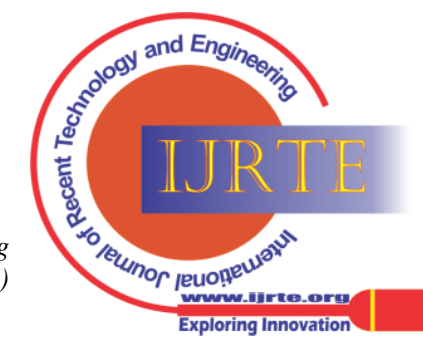

